\title{
Controlling Phase Separation of Lysozyme with Polyvalent Anions
}

DOI:

10.1021/acs.jpcb.8b10868

\section{Document Version}

Accepted author manuscript

Link to publication record in Manchester Research Explorer

\section{Citation for published version (APA):}

Bye, J. W., \& Curtis, R. A. (2019). Controlling Phase Separation of Lysozyme with Polyvalent Anions. The Journal of Physical Chemistry B, 123(3), 593-605. https://doi.org/10.1021/acs.jpcb.8b10868

\section{Published in:}

The Journal of Physical Chemistry B

\section{Citing this paper}

Please note that where the full-text provided on Manchester Research Explorer is the Author Accepted Manuscript or Proof version this may differ from the final Published version. If citing, it is advised that you check and use the publisher's definitive version.

\section{General rights}

Copyright and moral rights for the publications made accessible in the Research Explorer are retained by the authors and/or other copyright owners and it is a condition of accessing publications that users recognise and abide by the legal requirements associated with these rights.

\section{Takedown policy}

If you believe that this document breaches copyright please refer to the University of Manchester's Takedown Procedures [http://man.ac.uk/04Y6Bo] or contact uml.scholarlycommunications@manchester.ac.uk providing relevant details, so we can investigate your claim.

\section{OPEN ACCESS}


1 Controlling Phase Separation of Lysozyme with Polyvalent Anions

2 Jordan W. Bye a and Robin A. Curtis ${ }^{\mathrm{a} *}$

3 aschool of Chemical Engineering and Analytical Science, The University of Manchester,

4 Sackville Street, Manchester, M13 9PL, U.K.

$5 \quad *$ Corresponding author

6 Email: r.curtis@manchester.ac.uk

7 Telephone: $+44(0) 1613064401$

8

9

10

11

12

13

14

15

16

17

18

19

20

21

22

23

24

25

26

27

28

29

30

31

32

33

34

35

36

37 


\section{Abstract}

The ability of polyvalent anions to influence protein-protein interactions and protein net charge was investigated through solubility and turbidity experiments, determination of osmotic second virial coefficients $\left(B_{22}\right)$ and zeta potential values for lysozyme solutions. $B_{22}$ values showed that all anions reduce protein-protein repulsion between positively charged lysozyme molecules and those anions with higher net valencies are more effective. The polyvalent anions pyrophosphate and tripolyphosphate were observed to induce protein reentrant condensation, which has been previously observed with negatively charged proteins in the presence of trivalent cations. Reentrant condensation is a phenomenon in which low concentrations of polyvalent ions induce protein precipitation, but further increasing polyvalent ion concentration causes the protein precipitate to resolubilise. Interestingly, citrate anion does not induce lysozyme reentrant condensation despite having a similar charge, size and shape to pyrophosphate. We observe qualitative differences in protein behaviour when compared against negatively charged proteins in solutions of trivalent cations. The poly-phosphate ions induce a much stronger protein-protein attraction, which correlates with the occurrence of a liquid-gel transition that replaces the liquid-liquid transition observed with trivalent cations. The results indicate solutions of polyphosphate ions provide a model system for exploring the link between the protein phase diagram and model interaction potentials and also highlight the importance ion-specific effects can have on protein solubility. 


\section{Introduction}

The desire to understand the mechanism behind protein-protein interactions and how they can be modulated by the presence of co-excipients has attracted the attention of researchers for over a century. ${ }^{1-4}$ The desire to quantify the mechanisms of how cosolutes influence protein-protein interactions is important for understanding protein behaviours such as ligand binding, protein unfolding, crystallisation pathways, liquid-liquid phase separation (LLPS) and liquid-solid phase separation (LSPS). The need to understand protein phase behaviour in greater detail has been spurred on by the pharmaceutical industries ambition to develop stable liquid formulations of therapeutic biologics and provide a greater understanding into how biomolecular condensates form inside cells. ${ }^{5-13}$ The presence of certain cosolvents can improve biopharmaceutical solubility, stability and activity profiles when present in a formulation and are used by the industry to circumvent solubility and stability issues. ${ }^{1,7-8,14-18}$ Excipients are often discovered through large-scale screening and development of new solution additives, which aim to increase biopharmaceutical solubility, minimise poor rheological properties in concentrated formulations and maintain storage-stability for up to 2 years. A quantitative understanding of what makes certain additives solubilise, stabilise and improve activity is needed if future researchers are to take a more rational approach to formulation optimisation and understand cellular phase behaviour.

Salts are often integral components of formulations due to their ability to modulate protein solubility and thermal stability. Franz Hofmeister was the first to show that moderate-high concentrations of certain salts influence protein solubility in a consistent manner. This consistency enabled the salts to be ordered based on their ability to influence protein solubility into the Hofmeister series. ${ }^{1-2}$ This series has been found to exist in terms of how salts modulate protein thermal stability, water surface tension and viscosity. However, the exact mechanism is subject to active debate.,14-15,19-25 At lower salt concentrations (ionic strength $<100 \mathrm{mM}$ ), salts appear to modulate protein thermal stability and solubility via ion-specific interactions, which are inconsistent with the Hofmeister Effect. ${ }^{15,17,26-27}$ These inconsistencies appear to arise from differences in ion binding affinity and differences in protein surface topography. ${ }^{15,28-29}$ The effects of these ion-specific interactions in some cases follow the inverse Hofmeister series for anions and are reflected by the dual nature multivalent cations and anions have on the solubility of proteins (also termed reentrant condensation). ${ }^{6,26,28,30-31}$ they depend upon man factors such as the net charge of the protein, ion net charge, the ion species, ion concentration, protein concentration and the distribution of residues on the surface of the protein..$^{26-28,30-35}$

With positively charged proteins, the inverse Hofmeister effect is observed at low ionic strengths when chaotropic anions are more effective at decreasing protein solubility, but at higher ionic strengths protein solubility reverts back to classical Hofmeister 
120 behaviour. ${ }^{27-28,32}{ }^{36}$ For example the model protein lysozyme is least soluble under low ionic 121 strength conditions in the presence of thiocyanate and most soluble in the presence of 122 sulfate. ${ }^{27}$ The mechanism for the inverse Hofmeister effect has been rationalised from lower 123 critical solution temperature (LCST) studies of lysozyme. ${ }^{28,37}$ The LCST of a protein, also 124 known as the cloud-point temperature (CPT), corresponds to the temperature on-set of 125 protein precipitation upon cooling. Under low ionic strength conditions, electrostatic 126 repulsion between lysozyme molecules leads to increased solubility. Chaotropic anions 127 increase the CPT when they interact with positively charged surface residues and reduce the 128 surface charge of the protein which leads to an increase in protein-protein attraction. ${ }^{28,38}$ 129 Further increasing the chaotropic ion concentration causes the CPT to decrease (protein130 protein attractions become weaker) and protein resolubilisation occurs. The first phase has 131 been modelled through a Langmuir-type isotherm that describes the ability of the anions to 132 bind to the protein and neutralise the surface charge, which correlates with the anion 133 polarizability, which in turn, follows the inverse Hofmeister series. The second phase has 134 been attributed to hydration effects and how the anions modify the surface tension of the 135 solvent around the protein, which is related to the classical Hofmeister salting-in/out phenomenon. ${ }^{28,37,39}$

Trivalent cations such as yttrium $\left(\mathrm{Y}^{3+}\right)$, lanthanum $\left(\mathrm{La}^{3+}\right)$ and iron $\left(\mathrm{Fe}^{3+}\right)$ have a dual effect on the solubility of some proteins, which has been termed reentrant condensation. ${ }^{26,30}$ Addition of trivalent cations to a solution of human serum albumin (HSA), bovine serum albumin (BSA), ovalbumin and $\beta$-lactoglobulin cause protein precipitation, but further addition of trivalent cations causes the protein precipitate to resolubilise. The proteins previously listed are negatively charged under the experimental conditions used and repel each other through long-range electrostatics when no ions are present. Precipitation and resolubilisation occur at critical salt concentrations denoted by $c^{*}$ and $c^{* *}$, respectively that are roughly proportional to protein concentration indicating the boundaries occur at a constant ratio of ion to protein concentration. Initially, when trivalent cations bind to solvent exposed acidic residues there is neutralisation of the long-range electrostatic interactions and formation of short-ranged ion-bridging attractive forces between proteins. The combination of these effects causes protein condensation to take place at the critical salt concentration $c^{*}$ corresponding to when the proteins have net negative charge. At concentration $c^{* *}$ protein resolubilisation occurs, which has been attributed to either overcharging the protein by further binding of the trivalent cation or due to a charge screening effect. ${ }^{40-41}$ Solutions of negatively charged proteins and trivalent cations have been used as a model system for understanding the link between intermolecular interactions and phase behaviour as the condensed region contains a liquidliquid equilibrium, gel formation at higher protein concentrations, and cluster formation and/or amorphous precipitation at lower protein concentrations. The presence of the liquidliquid equilibrium is especially important because protein crystallization can be enhanced near to the phase boundaries. 
While the trivalent cation system provides a good model for understanding and controlling protein phase behaviour, it is of limited practical use for biopharmaceuticals production due to the toxic nature of the cations. However, it is feasible that similar behaviour can be induced using small multivalent anions. Small anions such as pyrophosphate (PP) and tripolyphosphate (TPP) are already approved by multiple regulatory bodies for use in foods and in cosmetics. ${ }^{42-44}$ Currently the effects of polyvalent anions on protein-protein interactions and protein phase behaviour are not well known or studied. Similar features to reentrant condensation have been observed to occur with polyvalent anions and proteins that have a net positive charge, most notably with the compound phytic acid (myo-inositol hexaphosphate, IP6). ${ }^{31,45-46}$ IP6 has a number of antinutritive properties linked to its ability to chelate positively charged metals and modulate the solubility of positively charged ingested and digestive proteins making them less available for the body to absorb, which causes the antinutritional effects. ${ }^{31,45-49}$ This was confirmed in a study by Bye et al 2012, phytic acid was seen to precipitate positively charged lysozyme but have no effect on the solubility of myoglobin and HSA which were neutrally and negatively charged respectively. ${ }^{31}$

There are other instances where re-entrant condensation does not occur for systems of multivalent ions and oppositely charged proteins. The multivalent cation spermidine is not capable of causing precipitation of negatively charged proteins, which has been attributed to the diffuse charge distribution on the polycation. ${ }^{50}$ Mellitate, a small multivalent anion, precipitates lysozyme at very low salt concentrations, but no resolubilisation occurs at higher salt concentration. ${ }^{51}$ As such, it is not clear to what extent the universal behaviour observed for trivalent metal cations with negatively charged proteins can be transferred to multivalent anions interacting with positively charged proteins.

As a first step towards addressing this issue, we determine how multivalent anions alter lysozyme phase behaviour and protein-protein interactions based on their ability to neutralise lysozyme charged groups. We show that the sodium salts of pyrophosphate (SPP) and sodium tripolyphosphate (STPP) induce lysozyme reentrant condensation, where the structures of SPP and STPP are shown in figure 1. It should be noted that the abbreviations STPP and SPP refer to the sodium salts of each anion, whereas the abbreviations PP and TPP refer to the pyrophosphate and tripolyphosphate anions respectively. It is likely the polyvalent anions effect protein interactions through similar mechanism of protein charge neutralization and ion-bridging effects, but the condensed phases have different properties from those formed in trivalent cation systems. We also show the trivalent anion citrate is incapable of inducing protein condensation, which highlights the important role of ion specific effects. ${ }^{31,46,52}$ The difference is likely due to the inability of citrate to cross-link proteins together even though it has nearly the same effectiveness as pyrophosphate at neutralizing the positive charge on lysozyme. 


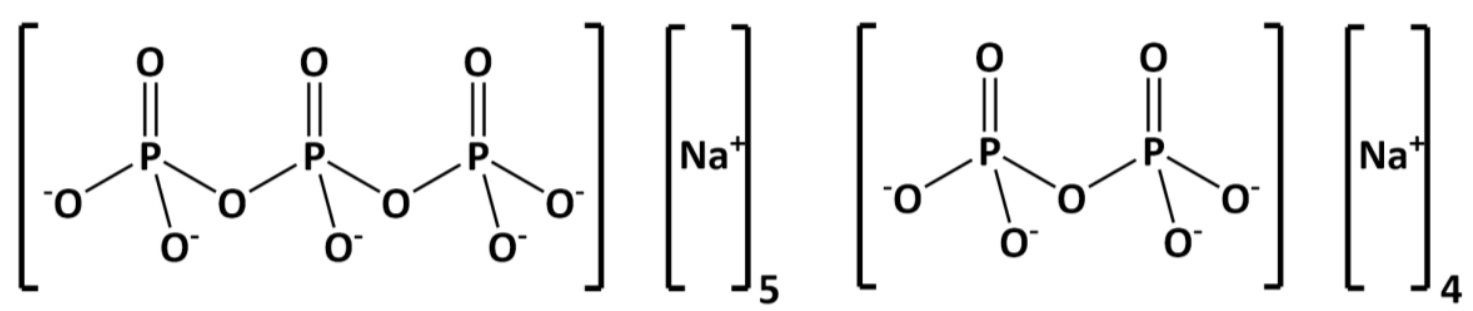

202

Figure 1. Structures for tripolyphosphate (STPP) anion (left) $\mathrm{pKa}_{1}: 1, \mathrm{pKa}_{2}: 2.2, \mathrm{pKa}_{3}: 2.3$, pKa 4 : 5.7, pKa $: 8.5$ and pyrophosphate (SPP) anion (right) $p K a_{1}: 0.91, p K a_{2}: 2.1, p K a_{3}: 6.7$, $\mathrm{pKa} \mathrm{a}_{4}: 9.32 .^{61}$ 


\subsection{Materials}

238

239

240

241

242

243

244

Lysozyme was sourced from Sigma Aldrich (Sigma Aldrich, Gillingham, U.K.) and used without further purification. Tris base, sodium chloride, monobasic sodium phosphate, dibasic sodium phosphate, disodium sulfate and trisodium citrate were sourced from Sigma Aldrich with purities $\leq 99 \%$. Sodium pyrophosphate (SPP) was sourced from Alfa Aesar, (Alfa Aesar, Heysham, U.K.) with a purity of $\leq 98 \%$ and sodium tripolyphosphate (STPP) was sourced from Fisher Scientific U.K. Ltd, (Fisher Scientific, Loughborough U.K.) with a purity of $\leq 99 \%$. Water sourced from a Milli- $Q^{\circledR}$ Advantage $A 10^{\circledR}$ water purification system (Merck, Darmstadt, Germany) with a resistivity of $18.2 \mathrm{M} \Omega . \mathrm{cm}$ was used as the solvent for all salt and protein solutions.

All buffer solutions used for dialysis and excipient solutions were prepared volumetrically and filtered with a $0.2 \mu \mathrm{m}$ hydrophilic nylon membrane (Merck Millipore Ltd., Ireland) regardless of the experiment being conducted. Ionic strength was calculated for each salt using literature $\mathrm{p} K_{\mathrm{a}}$ values and the Henderson-Hasselbalch equation. ${ }^{53}$

\subsection{Static Light Scattering Experiments}

Static light scattering (SLS) measurements were used to determine the osmotic second virial coefficient $\left(B_{22}\right)$ for lysozyme as a function of ionic strength. The value of $B_{22}$ is related to a separation and orientation averaged free energy of interaction between a pair of proteins. Positive values reflect net repulsive protein-protein interactions, while negative values relate to averaged attractive protein-protein interactions.

$10 \mathrm{~mL}$ stock lysozyme solutions were prepared and dialysed against $500 \mathrm{~mL}$ of the desired buffer solution for 4 hours twice and again overnight. After dialysis the $\mathrm{pH}$ of the lysozyme stock solution was adjusted to $\mathrm{pH} 9.0$ ( \pm 0.02 ). Next, the lysozyme stock solutions were adjusted to $20 \mathrm{mg} / \mathrm{mL}$; $\mathrm{pH}$ was checked and adjusted again after this step. Finally the lysozyme stock solution was passed through a $0.02 \mu \mathrm{m}$ Whatman Anotop syringe filter (Scientific Laboratory Supplies Ltd, Nottingham, U.K.).

SLS experiments were conducted on a Wyatt miniDAWN TREOS 3 angle $\left(49^{\circ}, 90^{\circ}\right.$ and $131^{\circ}$ ) detector (Wyatt Technology Corporation, Santa Barbara, CA 93117) with a flow cell; instrument details are given in a previous publication. ${ }^{8}$ Samples were delivered and mixed using a Wyatt Calypso II (Wyatt Technology Corporation, Santa Barbara, CA 93117), an automated syringe pump. The Calypso II contains three programmable syringe pumps capable of generating precise concentration step gradients. The flow from each syringe pump passes through an in-line $0.1 \mu \mathrm{m}$ pore size membrane. A static mixer is used to mix 
the streams after the filtration step before the sample enters the flowcell. In a typical light scattering experiment, pump 1 will uptake the protein stock solution, pump 2 will uptake a stock solution containing the co-solute and pump 3 will uptake the buffer solution. The Calypso II was then programmed to generate a series of experiments. $B_{22}$ values were obtained by decreasing the protein concentration in a linear stepwise fashion from the starting protein concentration $(10 \mathrm{mg} / \mathrm{mL})$ to zero concentration; this was repeated in the presence of different co-solute concentrations to assess how salts modulate $B_{22}$ values.

$B_{22}$ values can be calculated for a system containing protein, water and salt from

where $K$ is the light scattering constant $2 \pi^{2} n_{0}^{2} /\left(N_{\mathrm{A}} / \lambda^{4}\right), \mathrm{n}_{0}$ is the refractive index of the solvent, $\lambda$ is the wavelength of the light, $c$ is the protein concentration $(\mathrm{mg} / \mathrm{mL}),(\partial n /$ $\partial c)_{T, \mu_{w}, \mu_{\mathrm{s}}}$ is the refractive index increment of the protein (a value of $0.185 \mathrm{~mL} / \mathrm{g}$ was used) solution measured at a constant chemical potential of the water $\left(\mu_{w}\right)$ and salt $\left(\mu_{s}\right), \overline{R_{\theta}}$ is the measured excess Rayleigh scattering ratio of the protein solution over the solvent, $M$ is the molecular weight of the protein and $B_{22}$ is the osmotic second virial coefficient. The error bars reported on the values of $B_{22}$ correspond to the standard error in the slope estimate from plotting $K c / R_{\theta}$ versus protein concentration $(\mathrm{g} / \mathrm{mL})$. In some instances, error bars are not visible due to them being the same size or smaller than the corresponding symbols in the plot.

\subsection{Protein Precipitation and Turbidity Experiments}

$25 \mathrm{~mL}$ of $125 \mathrm{mg} / \mathrm{mL}$ lysozyme in $10 \mathrm{mM}$ tris buffer at $\mathrm{pH} 9.0$ was prepared and dialysed against $500 \mathrm{~mL}$ of $10 \mathrm{mM}$ tris three times for 4 hours and again overnight. After dialysis the $\mathrm{pH}$ of the lysozyme stock solution was adjusted to $\mathrm{pH} 9.0( \pm 0.02)$ and the stock solution was adjusted to $100 \mathrm{mg} / \mathrm{mL}$ lysozyme, $10 \mathrm{mM}$ tris buffer; $\mathrm{pH}$ was checked again after this step. Finally, the protein stock solution was filtered with a $0.02 \mu \mathrm{m}$ Whatman Anotop syringe filter. $420 \mathrm{mM}$ stock solutions of sodium tripolyphosphate (STPP) and 300 $\mathrm{mM}$ sodium pyrophosphate (SPP) in $10 \mathrm{mM}$ tris buffer at $\mathrm{pH} 9.0( \pm 0.02)$ were prepared. New stock solutions of lysozyme at 2, 10, 20, 40 and $60 \mathrm{mg} / \mathrm{mL}$ were prepared from the original $100 \mathrm{mg} / \mathrm{mL}$ stock solution. $500 \mu$ of the new lysozyme stock solutions were combined with $500 \mu \mathrm{l}$ of SPP-tris or STPP-tris solutions to give samples containing the desired lysozyme-SPP/STPP concentrations. After mixing, samples were allowed to equilibrate at $25^{\circ} \mathrm{C}$ for 1 hour before being centrifuged at 10,000 rpm for 2 minutes using a Heraeus Pico 17 Centrifuge (ThermoFisher Scientific Ltd., U.K.). The equilibration and centrifugation steps were repeated one more time. After the second centrifugation step the supernatant was collected and its $280 \mathrm{~nm}$ absorbance measured using a NanoDrop ${ }^{\mathrm{TM}}$ 
316 One/One ${ }^{C}$ Microvolume UV-Vis spectrophotometer (ThermoFisher Scientific Ltd., U.K.).

317 Absorbance values were then plotted against SPP and STPP concentration.

318

Turbidity experiments were conducted using a Brinkmann Probe Colorimeter PC 950 (STH Company, Cocoa Beach, FL 32931) at $490 \mathrm{~nm}$. All lysozyme solutions were prepared in the same manner as the precipitation experiments. Instrument transmittance was initially blanked to $100 \%$ for each lysozyme concentration. The starting volume of each lysozyme sample was $10 \mathrm{~mL}$ to which SPP and STPP were titrated into to give the desired SPP/STPP concentration while the sample was continuously stirred. For $1,5,10$ and $20 \mathrm{mg} / \mathrm{mL}$ lysozyme samples transmission readings were taken every 2 minutes after SPP/STPP addition. For 30 and $50 \mathrm{mg} / \mathrm{mL}$ lysozyme readings were taken every 5 minutes until transmittance reached zero.

\subsection{Zeta Potential Measurements}

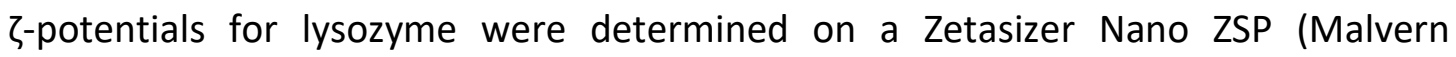
Instruments Ltd., Malvern, U.K.) using DTS1070 folded capillary cells (Malvern Instruments Ltd., Malvern, U.K.). A $10 \mathrm{mg} / \mathrm{mL}$ stock solution of lysozyme was prepared and filtered using

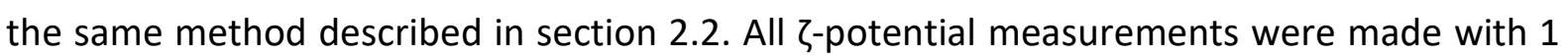
$\mathrm{mg} / \mathrm{mL}$ protein in $10 \mathrm{mM}$ tris buffer at $\mathrm{pH} 9.0( \pm 0.02)$ for lysozyme (the relatively low 1 $\mathrm{mg} / \mathrm{mL}$ lysozyme concentration was used to ensure that phase-separation could be avoided for most SPP and STPP samples). All $\zeta$-potential measurements were conducted with the same applied voltage $(40 \mathrm{~V})$. In this study an $F(k a)$ of 1.5 (i.e. Smoluchowski's approximation) and the dielectric constant of water were used. All experiments were run at $25{ }^{\circ} \mathrm{C}$, the sample was allowed to equilibrate for 300 seconds before the measurements were made, 10 measurements were collected and averaged for each ionic strength tested and were repeated six times. In figures $3 A$ and $3 B$ it should be noted that standard deviations were calculated for all data points, but the standard deviation for some points was small enough that the bars do not appear over the data point.

\section{Results}

\section{The Effect of Increasing Anion Valency on Lysozyme-Lysozyme Interactions}

The effect of increasing ionic strength by adding different salts on the osmotic second virial coefficient $\left(B_{22}\right)$ of lysozyme at $\mathrm{pH} 9.0$ was assessed through static light scattering (SLS); these results are reported in figure 2, molecular weights for each condition tested are given in table S1. Positive $B_{22}$ values at low ionic strength indicate strong repulsion between positively charged lysozyme molecules. ${ }^{7,54-55}$ Increasing the concentration of each salt causes $B_{22}$ values to decrease and plateau at slightly negative values. The main effect of changing ionic strength in the range of $0-100 \mathrm{mM}$ is to alter 
electrostatic interactions between proteins. At $\mathrm{pH}$ 9.0, titration experiments indicate lysozyme has a net charge of around $+6-7 e .^{56}$ The positive charge on lysozyme gives rise to repulsive double layer forces under low ionic strength conditions. Increasing ionic strength compresses the double layer and reduces the range of the force causing the observed decrease in $B_{22}$ values and the plateauing behaviour observed at higher ionic strengths $(>100 \mathrm{mM}) .^{54,57-58}$

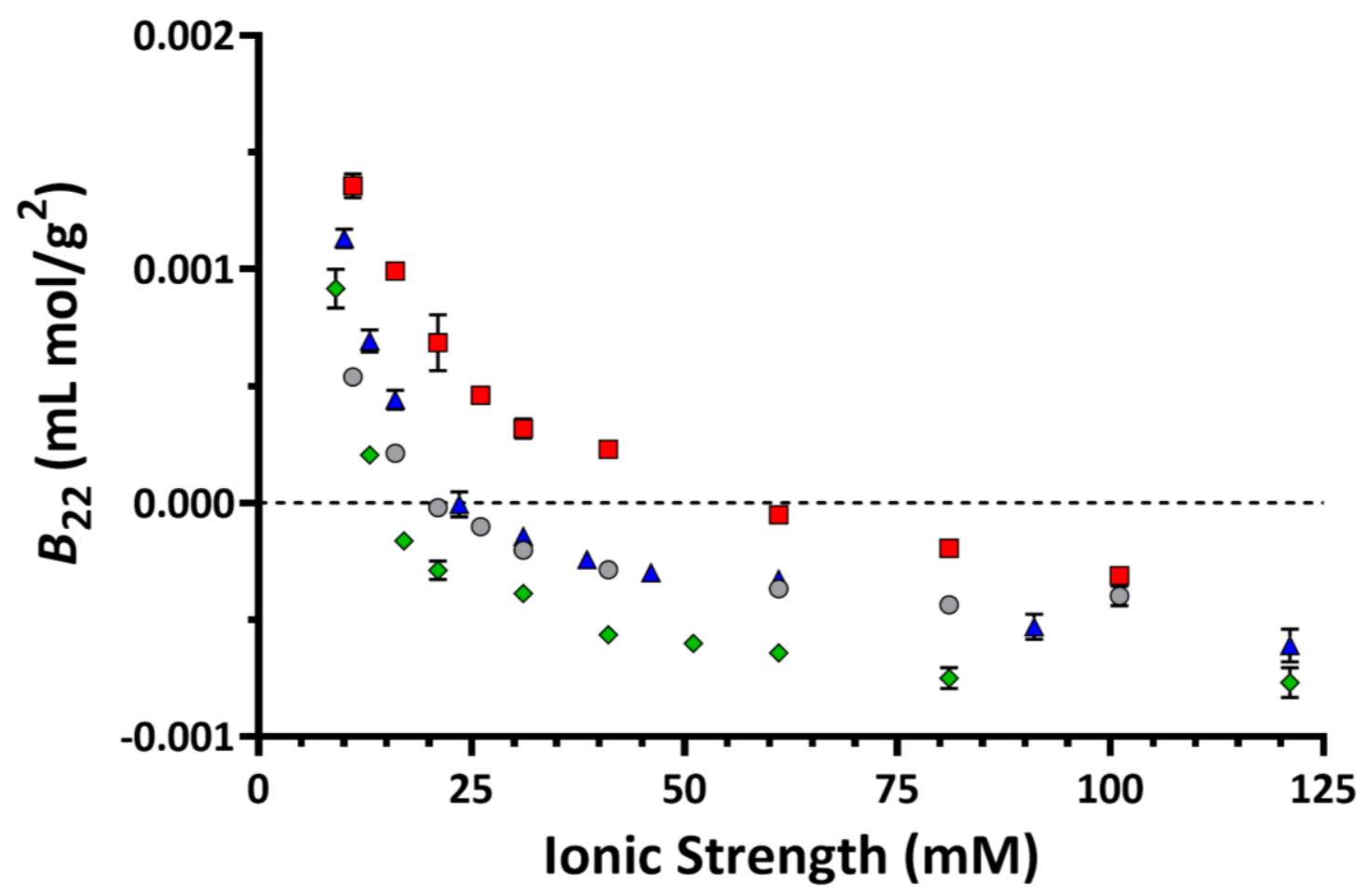

363

364

Figure 2. Experimental data for $B_{22}$ values of lysozyme as function of chloride ( $\left.\mathbf{\square}\right)$, phosphate $(\bullet)$, sulfate $(\boldsymbol{\Delta})$ and citrate $(\bullet)$ ionic strength in $10 \mathrm{mM}$ tris buffer (ionic strength contribution $1.05 \mathrm{mM}$ ) at pH 9.0.

The trends of $B_{22}$ with respect to salt type indicate how anions with increasing charge influence the strength of lysozyme-lysozyme interactions. Anions with higher valencies are more effective at reducing lysozyme-lysozyme repulsion under low ionic strength conditions. This pattern of protein-protein interactions, when comparing the sodium salts of phosphate, sulfate and citrate, has been previously observed for a monoclonal antibody and rationalized in terms of a charge neutralization mechanism effecting electrical double layer forces. ${ }^{8,18}$ At a given ionic strength condition, the double layer force depends on the fixed charge of the protein including any tightly bound ions contained in the stern layer. As such, the increased efficiency of the ions at reducing protein-protein interactions is likely due to their ability to bind to and neutralise the positive charge of the basic residues. Ions with increasing valency are more effective because binding is in part driven by electrostatic interactions, which are stronger with the increase in 
ion charge. It appears that the ion binding only alters the electrostatic interactions between proteins as anion-specific differences are reduced under high ionic strength conditions.

$\zeta$-potential measurements shown in figures $3 A$ and $3 B$, were used to determine how different anions influence the fixed charge of lysozyme. The $\zeta$-potential reflects the electrostatic potential at the slip plane of the protein, which depends on the charge that is immobilized on the protein including any counterions or co-ions. When comparing the $\zeta-$ potential measured at a fixed ionic strength for lysozyme in different salt solutions, the difference arises due to changes in the number of anions bound to the protein. As such, the decrease observed in the solutions of multivalent anions reflects the initial neutralization of the positive charge. The same pattern of ion binding is found as deduced from the $B_{22}$ trends, where the ability of the anion at neutralizing the lysozyme positive charge follows the order citrate $>$ sulfate $>$ chloride. The increased binding affinity of multivalent anions such as sulfate or citrate to proteins has also been observed from calculating the effective charge $\left(Q^{*}\right)$ of lysozyme in the presence of different salts and simulation studies. ${ }^{59-60}$ The poly-phosphate anions are more effective at neutralizing the protein due to their larger ion valency when compared against citrate.

398

399

400

401

402

403

404

405

406

407

408

409

410

411

412

413

414

415

416

417

418

419

420

421

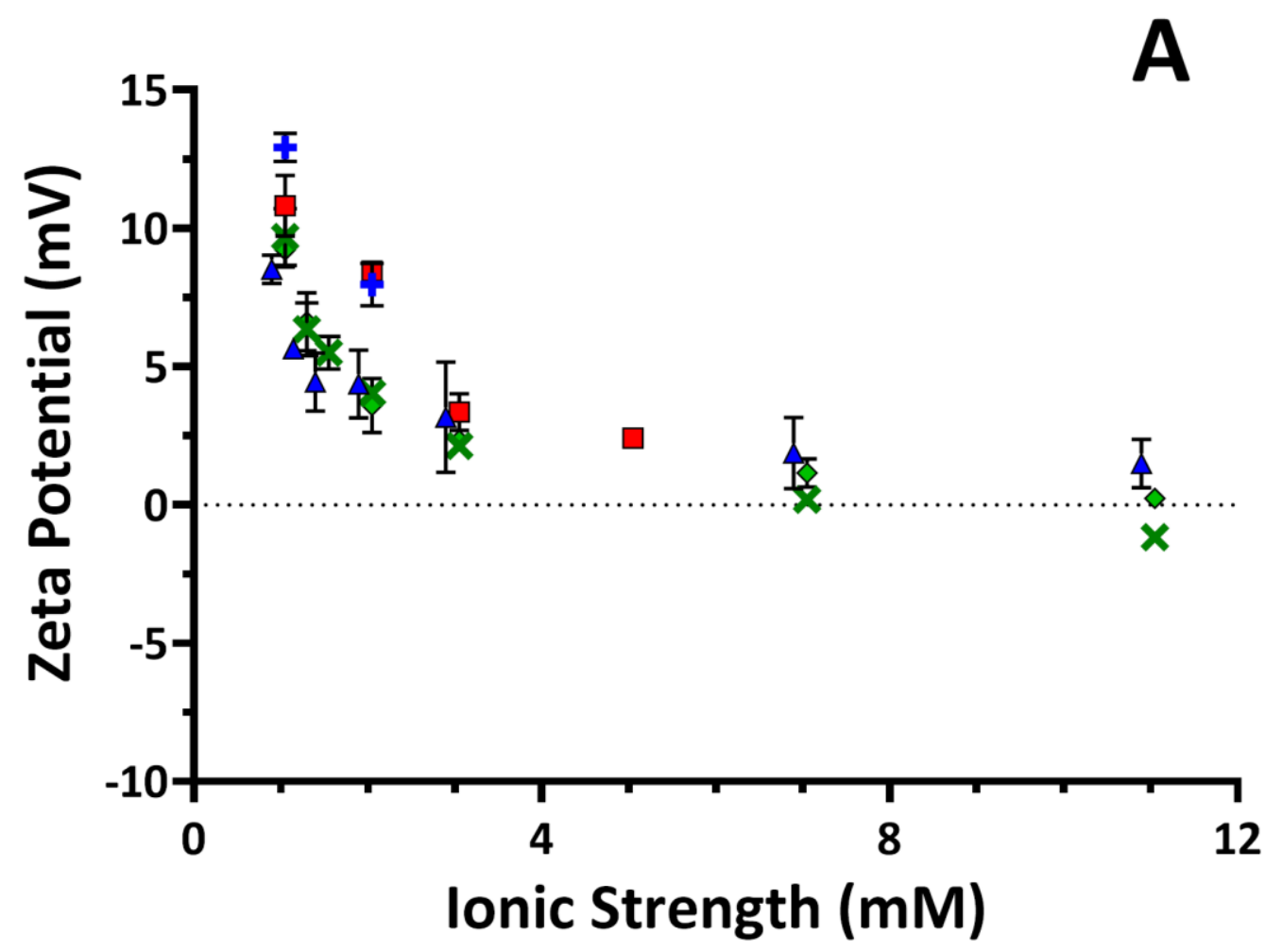


Figure 3. (A) Zeta potentials for $1 \mathrm{mg} / \mathrm{mL}$ lysozyme in the presence of $0-12 \mathrm{mM}$ ionic strength $\mathrm{NaCl}(\boldsymbol{\square})$, sulfate $(\mathbf{A})$, citrate $(\bullet)$, SPP $(\mathbf{X})$ and $\operatorname{STPP}(\mathbf{+})$ in $10 \mathrm{mM}$ tris at pH 9.0. (B) $1 \mathrm{mg} / \mathrm{mL}$ lysozyme in the presence of $0-200 \mathrm{mM}$ ionic strength $\mathrm{NaCl}(\boldsymbol{\nabla})$, sulfate $(\mathbf{\Delta})$, citrate $(\diamond), \operatorname{SPP}(\mathbf{X})$ and STPP (+) in $10 \mathrm{mM}$ tris at $\mathrm{pH}$ 9.0. Tris Buffer ionic strength contribution is $1.05 \mathrm{mM}$ at $\mathrm{pH} 9.0$.

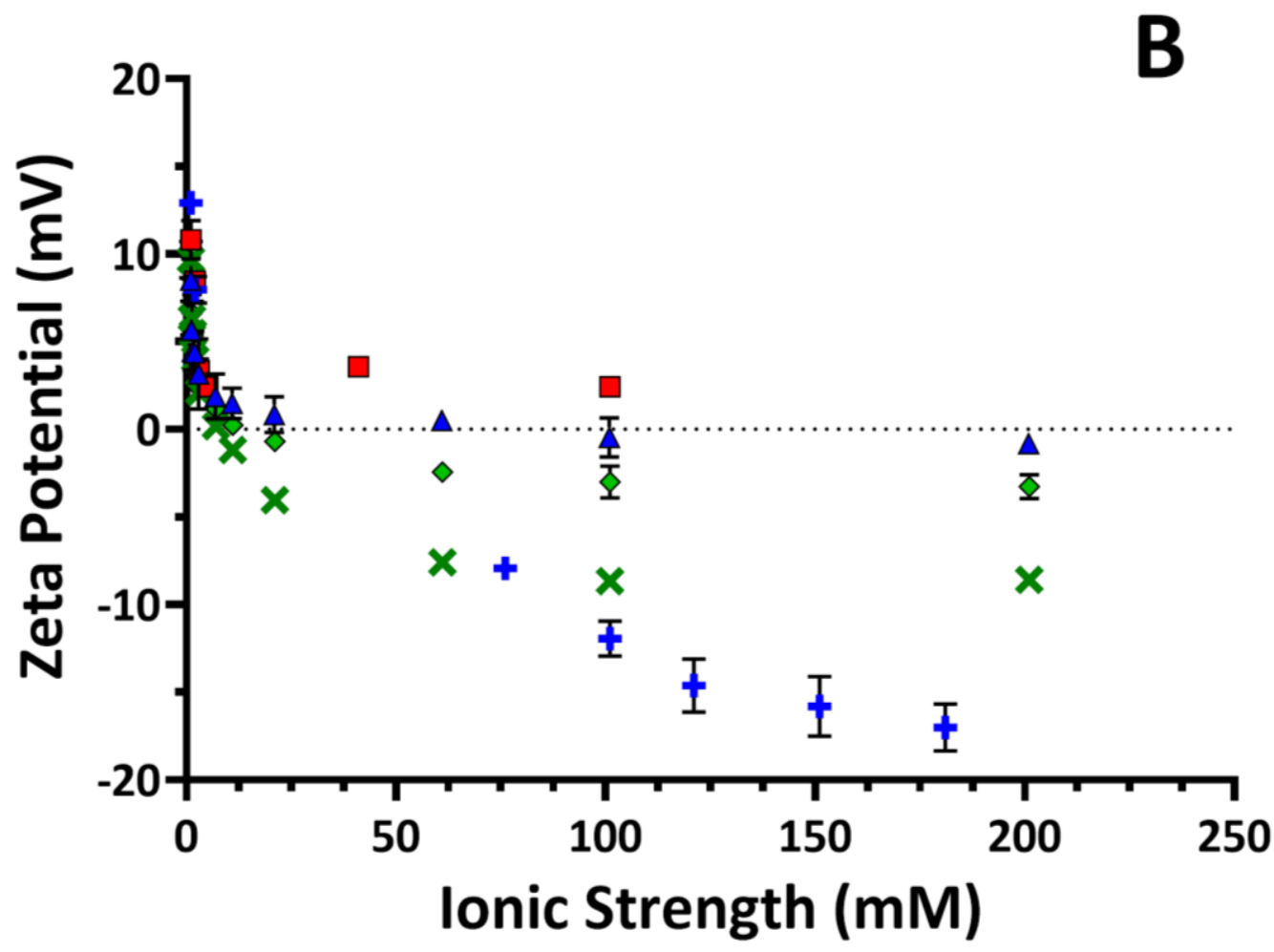

The $\zeta$-potential measurements indicate lysozyme net charge decreases quickly at low ionic strengths and plateaus at a negative value at higher ionic strengths indicating the multivalent anions overcharge the protein. The magnitude of the charge inversion also follows what is expected based on the ion valency as the overcharging effect follows the order TPP > PP > citrate > sulfate, where the average charge of PP and TPP at pH 9.0 are equal to $-3.32 e$ and $-4.76 e$ respectively. ${ }^{61}$

The protein-protein interactions measured in the solutions containing polyphosphate ions indicates the protein behaviour differs qualitatively to what happens in solutions with citrate or sulfate ions. It was hypothesised that there would be a nonmonotonic dependence of $B_{22}$ in poly-phosphate solutions as protein-protein interactions should initially be screened by increasing salt concentration followed by an increase in 
repulsion due to over-charging. However, values of $B_{22}$ could not be determined at low ionic strengths $(<300 \mathrm{mM})$ of SPP or STPP due to lysozyme phase separation occurring at the protein concentrations used in the light scattering analysis. $B_{22}$ values were obtained at higher ionic strengths as shown in figure 4 . The inset of figure 4 shows that the $B_{22}$ values of SPP and STPP overlap when they are plotted as a function of molar concentration. $B_{22}$ values become more negative as the ionic strength of SPP and STPP is decreased below $1 \mathrm{M}$, indicating an increase in protein-protein attraction much stronger than that observed in other salt solutions. Further reducing ionic strength is expected to lead to an even greater protein-protein attraction, which would explain why lysozyme precipitates in solutions with low poly-phosphate concentrations conditions. Conversely, at high ionic strengths, proteinprotein interactions are more repulsive in solutions containing either SPP or STPP versus $\mathrm{NaCl}$. The change in protein-protein interactions occurs over an ionic strength range where electrostatics should be screened indicating approaches based on the Poisson-Boltzmann equation cannot be used to rationalize all the effects of the polyvalent anions.

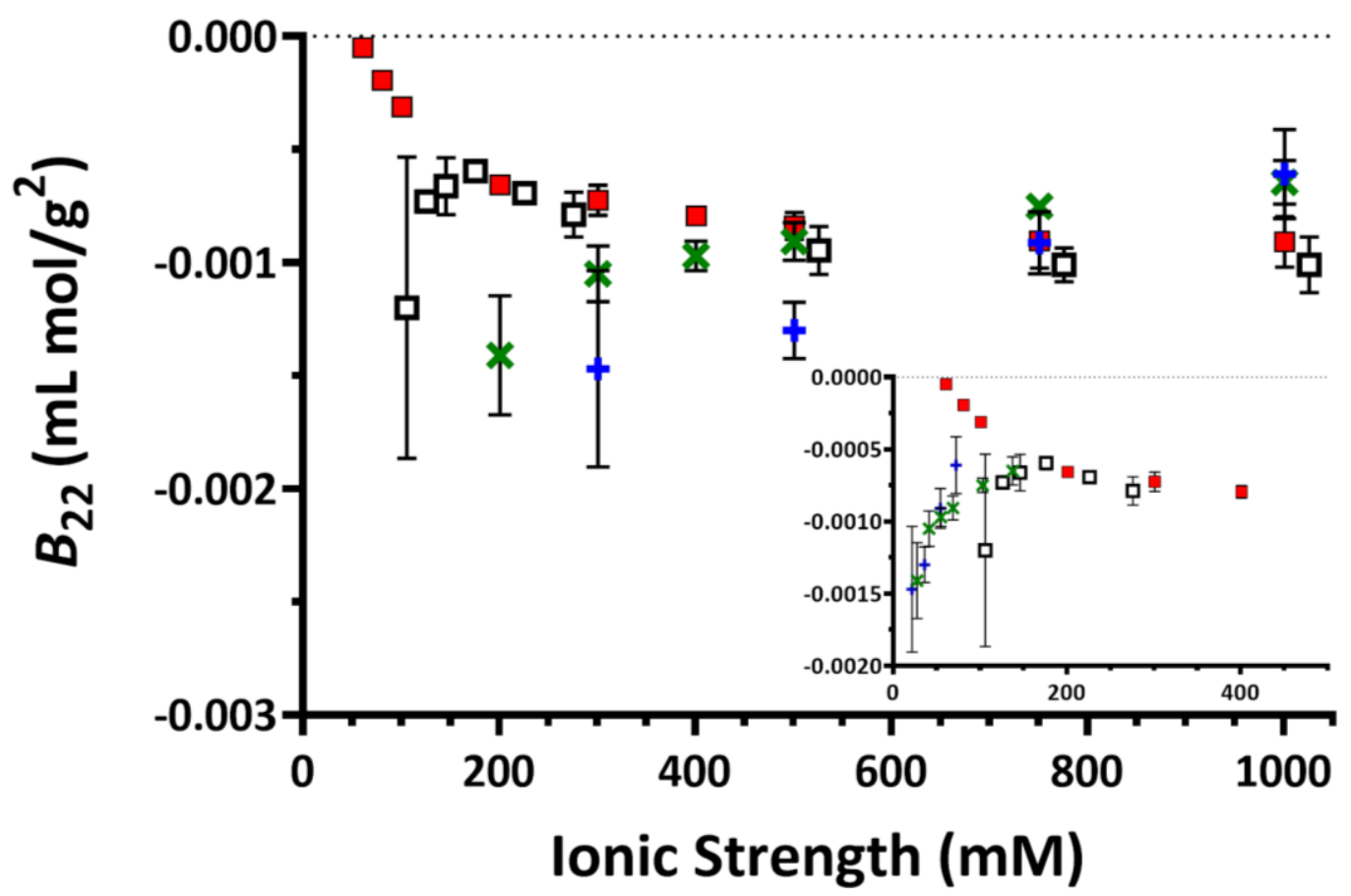

Figure 4. Experimental data for $B_{22}$ values for lysozyme as function of ionic strength for chloride (四), NaCl+25 mM (1.812 mM) STPP ( $\mathbf{\square})$, SPP (X) and STPP (+) in $10 \mathrm{mM}$ tris Buffer (ionic strength contribution $1.05 \mathrm{mM}$ ) at $\mathrm{pH}$ 9.0. Insert shows molar concentrations for all salts tested.

In order to further investigate how the poly-phosphate ions modulate proteinprotein interactions, we determined $B_{22}$ values as a function of sodium chloride 
concentration in solutions with a fixed STPP concentration of $1.812 \mathrm{mM}$, which corresponds to an ionic strength contribution from the salt equal to $25 \mathrm{mM}$. Measurements were only possible once the concentration of $\mathrm{NaCl}$ was greater than $80 \mathrm{mM}$. With increasing $\mathrm{NaCl}$ concentration, there is a weakening of the protein-protein attraction induced by the TPP. At higher concentrations of $\mathrm{NaCl}, B_{22}$ values start to overlap with those obtained in solutions with no SPP or STPP. If the only effect of $\mathrm{NaCl}$ is to screen protein-protein interactions, then we would expect a monotonic increase in $B_{22}$ values as electrostatic interactions between proteins are weakened with increasing salt concentration. As such, the non-monotonic dependence of $B_{22}$ reflects a combination of effects. We suggest the initial addition of $\mathrm{NaCl}$ screens TPP binding to the protein, which in turn, weakens any protein-protein attraction induced by the TPP. At a critical $\mathrm{NaCl}$ concentration, there is no TPP binding and the $B_{22}$ values follow the curves obtained in the absence of TPP, where the main effect of sodium chloride is to screen the repulsive electrostatic interactions between proteins. A similar behaviour has been previously observed to occur with IP6. Low concentrations of IP6 were shown to decrease the thermal stability of lysozyme, myoglobin and HSA as measured by differential scanning calorimetry (DSC), which is due to IP6 binding protein surface through electrostatic interactions causing distortion of the peptide backbone and tertiary structure of the protein. ${ }^{31}$ Adding $\mathrm{NaCl}$ to the solutions caused an increase in protein structural stability, which was attributed to displacing the IP6 molecules from the proteins through a salt screening effect. ${ }^{31}$

\section{Reentrant Condensation of Lysozyme by the Polyvalent Anions Pyrophosphate and Tripolyphosphate but not Citrate}

We initially mapped out precipitation phase boundaries by preparing a range of solutions at multiple lysozyme concentrations between $1-100 \mathrm{mg} / \mathrm{mL}$ and SPP or STPP concentrations between $0-210 \mathrm{mM}$. In some of the samples an amorphous solid precipitate formed immediately after preparing the solution. In these cases, the solid-phase was separated from the liquid-phase by centrifuging the sample at 10,000 rpm for 2 minutes and the supernatant concentration was measured. Figure $5 \mathrm{~A}$ shows a plot of protein concentration in the supernatant phase as a function of STPP concentration for different initial protein concentrations (an equivalent plot for SPP is shown in figure S2A). The flat parts of the precipitation profiles correspond to solutions where there is no lysozyme precipitation. The behaviour follows what is expected for reentrant condensation. An initial increase of salt concentration causes protein precipitation, where the critical concentration of SPP or STPP that causes protein precipitation is denoted by $c^{* \mathrm{p}}$. A superscript $\mathrm{p}$ is used to denote that the boundary corresponds to a precipitation experiment. The amount of lysozyme precipitated from solution by SPP or by STPP reaches a maximum as indicated by the lowest protein concentration on each curve. Increasing the concentrations of SPP and 
532

533

534

535

536

537

538

539

540

541

542

543

545

546

547

548

549

550

551

552

553

554

555

556

557

558

559

560

561

562

563

564
STPP past this point results in an increase in supernatant protein concentration followed by full protein resolubilisation at a poly-phosphate concentration denoted here as $c^{* \mathrm{P}}$.
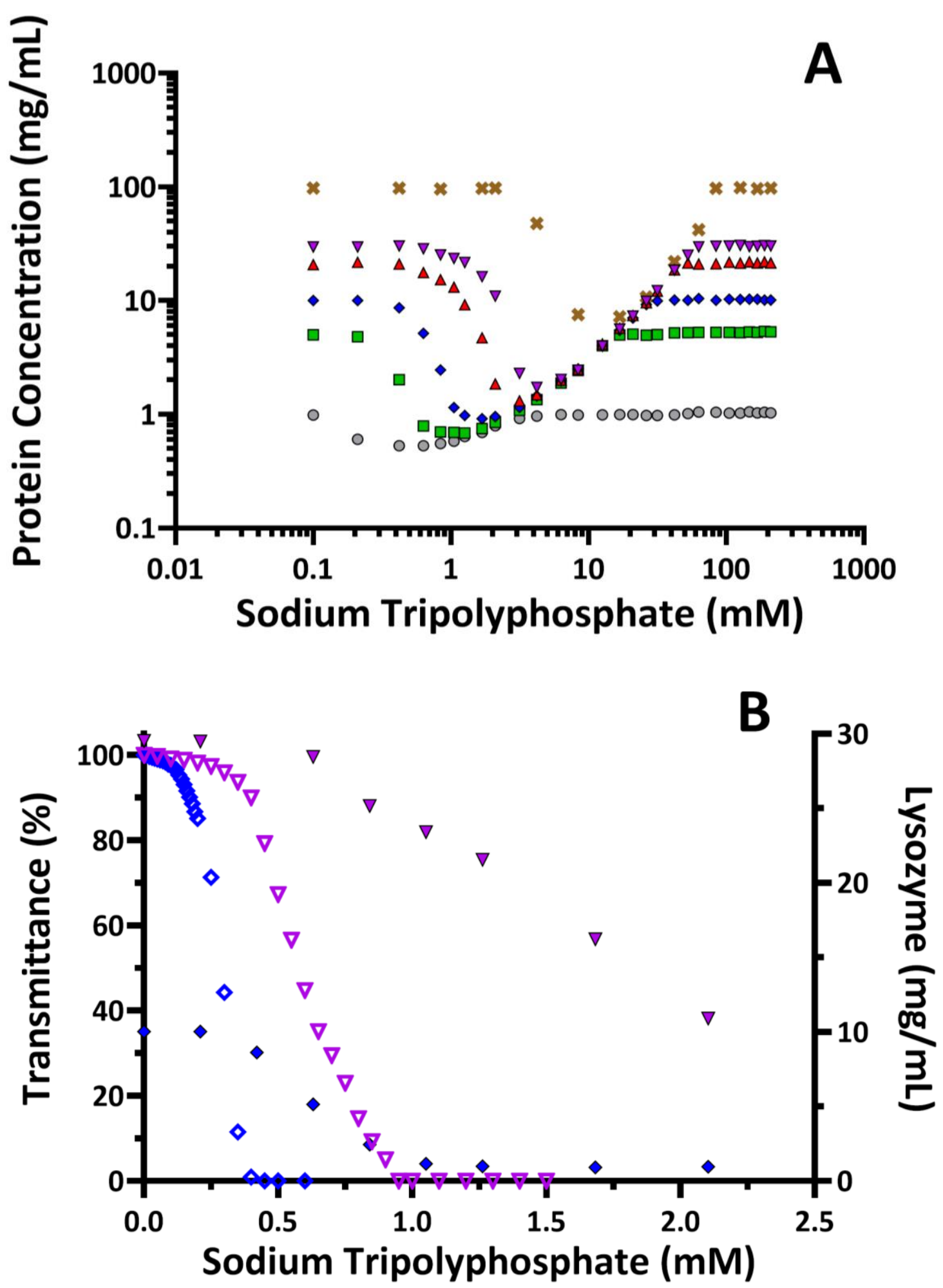

Figure 5. (A) Data for lysozyme precipitation experiments tested at $1 \mathrm{mg} / \mathrm{mL}(\bullet), 5 \mathrm{mg} / \mathrm{mL}$ $(\boldsymbol{\square}), 10 \mathrm{mg} / \mathrm{mL}(\boldsymbol{\vee}), 20 \mathrm{mg} / \mathrm{mL}(\mathbf{\Delta}), 30 \mathrm{mg} / \mathrm{mL}(\boldsymbol{\nabla})$ and $100 \mathrm{mg} / \mathrm{mL}(\mathbf{X})$ in $10 \mathrm{mM}$ tris $\mathrm{pH} 9.0$ 

direct comparison between SPP and STPP with 10 and $30 \mathrm{mg} / \mathrm{mL}$ lysozyme given in figure S3. First, for SPP or STPP, more poly-phosphate ions are needed to precipitate higher concentrations of lysozyme. Second, STPP is more effective than SPP at precipitating lysozyme as the initial precipitation occurs at lower STPP concentrations and the solubility of lysozyme at the maximum precipitation point is lower for STPP than for SPP. Lastly, the resolubilisation part of the curve at higher lysozyme concentrations appears similar for SPP and STPP (figure S3). The offset at lower lysozyme concentrations could be due to the greater amount of lysozyme having to be resolubilised when STPP is used as the precipitant.

In addition we have carried out turbidimetric titrations by adding SPP or STPP to lysozyme solutions. Example plots of the titrations for solutions of lysozyme at either 10 $\mathrm{mg} / \mathrm{mL}$ or $30 \mathrm{mg} / \mathrm{mL}$ in STPP solutions are compared against the turbidity titrations in figure $5 \mathrm{~B}$. The boundary $c^{*}$ was taken to occur when transmittance reached $95 \%$ with increasing salt concentration. For STPP the boundary $c^{*}$ occurs at lower STPP concentrations than $c^{* \mathrm{P}}$, whereas for SPP the $c^{*}$ and $c^{* \mathrm{P}}$ boundaries overlap at equivalent lysozyme concentrations. A slight decrease in turbidity occurs in solutions containing $1 \mathrm{mg} / \mathrm{mL}$ lysozyme and SPP, despite no observable precipitation occurring. The turbidity titrations were also used to determine the $c^{* *}$ boundary corresponding to the salt concentration when the transmittance of the solution returned to $100 \%$. In contrast to the $c^{*}$ boundaries, the $c^{* *}$ values determined by turbidimetric titrations coincided with the corresponding values determined by the precipitation experiments for solutions containing either SPP or STPP.

The phase behaviour observed here is similar to the reentrant condensation behaviour reported for trivalent cations with negatively charged proteins. ${ }^{6,26,30,33}$ Figure $6 \mathrm{~A}$ and $6 \mathrm{~B}$ show the phase diagram of lysozyme in the presence of SPP and STPP containing the boundaries $c^{*}, c^{* \mathrm{P}}$, and $c^{* * \mathrm{P}}$, which demarcate the different types of protein solution behaviour. Lysozyme is fully soluble in solutions located below the $c^{*^{p}}$ boundary, solidliquid phase separation occurs at locations between $c^{* \mathrm{P}}$, and $c^{* * \mathrm{P}}$, and lysozyme resolubilisation occurs above $c^{* * \mathrm{p}}$. Following the trivalent cation work, we denote region I and III to occur below $c^{*}$ and above $c^{* \mathrm{p}}$ respectively, while region II is located between those boundaries. The turbidity titrations have confirmed the existence of cluster formation in regions located between $c^{*}$ and $c^{* \mathrm{p}}$ for STPP and for solutions of SPP to the left of the solidliquid equilibrium. We have not observed any lysozyme crystallization to occur in the cluster region, which is in direct contrast to solutions with trivalent cations, where the clustering region leads to protein crystal formation. ${ }^{30,62}$ Another key difference is that the liquid-liquid 
equilibrium observed in solutions with trivalent cations has been replaced with a solid-liquid equilibrium in poly-phosphate containing solutions.
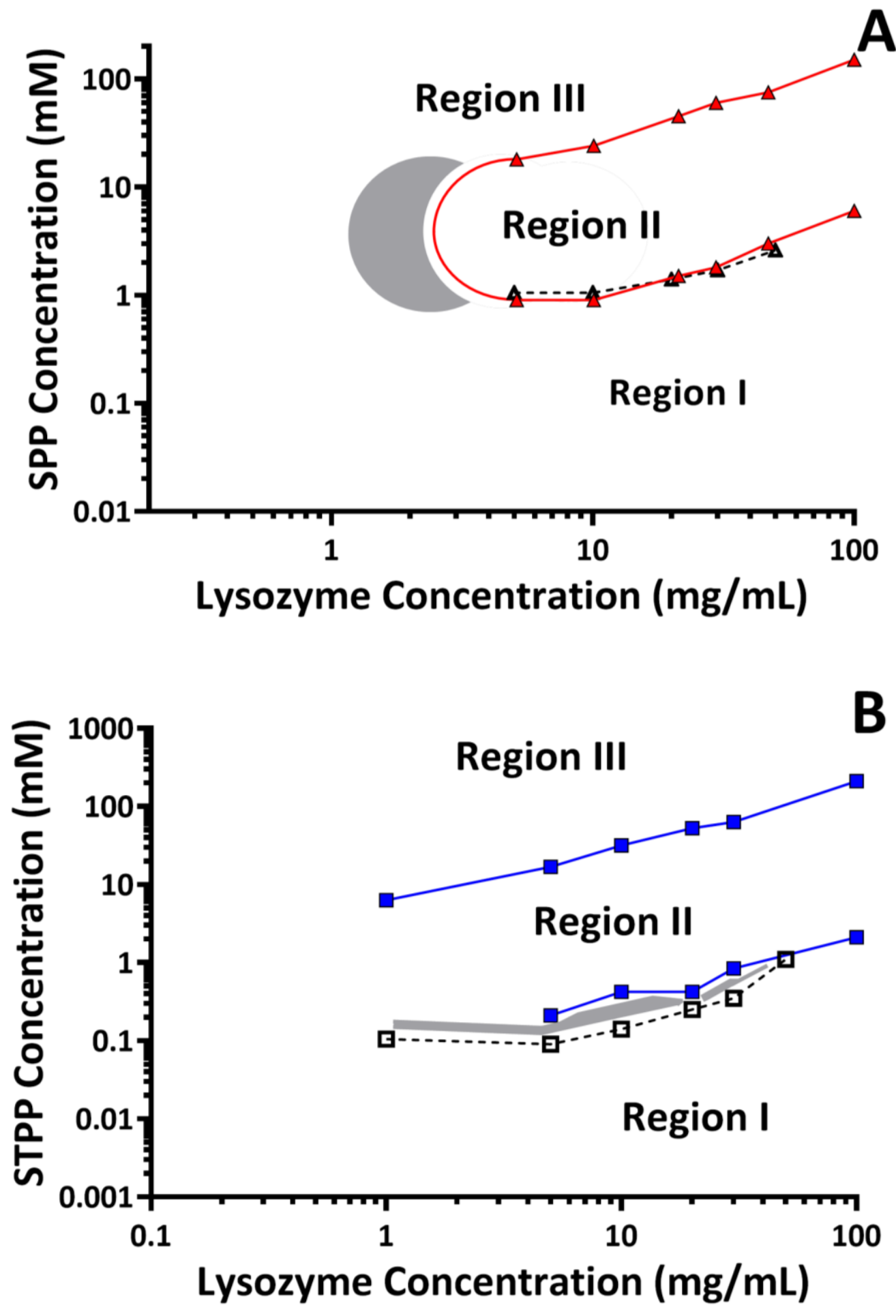

Figure 6. Phase diagram of lysozyme as a function of SPP (A), STPP (B) and lysozyme concentration in $10 \mathrm{mM}$ tris $\mathrm{pH} 9$ buffer. Solid data points on the lower solid line in $A$ and $B$ were taken as the point lysozyme precipitation starts to occur $\left(c^{* \mathrm{P}}\right)$ and the data points on the top solid lines were taken when full lysozyme resolubilisation occurs $\left(c^{* * \mathrm{p}}\right)$. The dashed 

line with open symbols in A and B were determined from turbidity experiments and are when transmittance decreased to $95 \%\left(c^{*}\right)$ from increasing SPP and STPP concentration. Shaded areas indicate regions where cluster formation takes place.

Sodium citrate does not induce reentrant condensation of lysozyme when studied under the same conditions as SPP (sodium citrate concentration was varied from 0-167 mM in the presence of $10-50 \mathrm{mg} / \mathrm{mL}$ lysozyme) even though citrate was observed to influence lysozyme net charge in a similar way to SPP. The similar neutralization ability is expected as citrate anion is similar to PP in size, shape and charge at $\mathrm{pH} 9.0$; the $\mathrm{pKa}$ values for citrate are 3.13, 4.76 and 6.39 which would give citrate a net charge of $-3 e$ at pH 9.0; PP has a net charge of $-3.32 e$ at $\mathrm{pH}$ 9.0. The lack of precipitation in citrate solutions is expected from the $B_{22}$ measurements which indicate citrate ion appears to only neutralize the double layer forces, but does not induce any additional protein-protein attraction to that which occurs once electrical double-layer forces are screened.

\section{Discussion}

\section{The re-entrant condensation occurs due to ion binding followed by overcharging}

The combined electrophoretic light scattering and precipitation experiments indicate poly-phosphate ions induce a similar phenomenon as observed with trivalent cations. ${ }^{30,50}$ With increasing concentration of multivalent ions, a drop in the electrophoretic mobility due to ion binding and neutralization of charged groups coincides with the initial precipitation boundary. At higher ionic concentrations, additional ion binding leads to protein charge reversal and an overcharging effect that resolubilises the protein. ${ }^{30,50,63}$ The minimum solubility occurs between the two when the fixed charge on the protein is close to zero. The solubility correlation is due in part to the effects of repulsive double layer forces, which increase with the net charge of the protein. ${ }^{7,64-65}$ When the forces are removed by neutralizing the protein charge through ion binding, condensation or precipitation occurs due to the attractive contributions to protein-protein interactions. The intrinsic shortranged attractions between proteins, which are still poorly understood, can originate from dispersion forces, hydrogen bonding, or hydrophobic interactions. ${ }^{66-69}$

Trivalent cation binding to negatively charged proteins induces an additional shortranged protein-protein attraction due to an ion-bridging mechanism. ${ }^{30,50,63}$ The existence of this force was deduced by Jordan et al 2014 from the solubility patterns of BSA. BSA is soluble at its isoelectric point indicating the absence of double layer forces is not enough to cause BSA precipitation, whereas precipitation of BSA occurs readily in the presence of trivalent cations. ${ }^{63}$ An additional protein-protein attraction has also been observed indirectly from fitting a two-yukawa model to structure factor profiles obtained from SAXS 
data for BSA solutions. ${ }^{70} \mathrm{~A}$ much stronger attraction was required to fit the experimental data in solutions containing $\mathrm{FeCl}_{3}$ or $\mathrm{NiCl}_{2}$ versus $\mathrm{NaCl}$. The ion-bridging mechanism is also evident from crystallization behaviour of $\beta$-lactoglobulin, which forms a unique crystal structure when precipitated using solutions of $\mathrm{YCl}_{3}{ }^{71}$ The yttrium ions form bridges between two or three carboxylate groups in protein crystal contacts that do not occur in other crystal forms for $\beta$-lactoglobulin.

The ion-bridging attraction in lysozyme solutions is evident when comparing the behaviour in poly-phosphate solutions to the other salts investigated here. The proteinprotein attraction which results from only neutralizing double layer forces should be reflected by the $B_{22}$ values at higher ionic strength, where electrostatics have been sufficiently screened, or in solutions of salts with multivalent cations, such as citrate or phosphate, once the protein has been neutralized through ion binding. In citrate solutions, the protein is neutralized above an ionic strength of $20 \mathrm{mM}$, which corresponds to a $B_{22}$ value equal to $-2.9 \times 10^{4} \mathrm{~mL} \mathrm{~mol} / \mathrm{g}^{2}$, which is also similar to the value obtained at higher ionic strength for the other salts. None of these salt solutions have been observed to cause protein precipitation. In particular, in the citrate solutions at concentration ranging from 0 to $167 \mathrm{mM}$, the solution remains in one phase up to a protein concentration of $50 \mathrm{mg} / \mathrm{ml}$. In contrast, the solubility of lysozyme in SPP and STPP solutions is as low as $1 \mathrm{mg} / \mathrm{mL}$ indicating the presence of a much stronger protein-protein attraction, which is required to stabilize the precipitated state. The presence of an additional attraction is also apparent when comparing the $B_{22}$ values shown in figure 4 . The values in the poly-phosphate solution are much more negative at intermediate poly-phosphate concentrations when compared against any of the other salts. The extra protein-protein attraction is likely due to a similar ion-bridging mechanism as observed for trivalent cation systems. The multivalent property of the poly-phosphates provides it with the ability to cross link basic residues together.

\section{lon-bridging attraction induced by poly-phosphates is stronger than trivalent cations}

More insight into the nature of the ion-bridging force can be gained from considering the location of the lower phase boundary $c^{*}$. In solutions containing trivalent cations, the boundary has been described using an empirical relationship given by

$$
c^{*}=c^{f}+m^{*} c_{\mathrm{p}}
$$

where $c_{p}$ is protein concentration. Equation 2 is applicable when the initial precipitation at the $c^{*}$ boundary occurs at a critical value of bound multivalent ions per protein given by $m^{*}{ }^{50,63} c^{f}$ in turn is the free solution salt concentration that is in equilibrium with the protein complex when it has $m^{*}$ bound ions, which is independent of protein concentration as long as protein-protein interactions are negligible. In order to check the validity of equation 2 , in the supplementary information the data shown in figure 4 has been replotted 
as a function of the salt concentration normalized by $c_{\mathrm{p}}$ (figure S1A and S1B) where we use the boundary $c^{* \mathrm{p}}$ rather than $c^{*}$. The curves obtained at higher protein concentration begin to decrease at the same point, which is expected when $m^{*} c_{\mathrm{p}}>c^{f}$. This corresponds to the case where the concentration of complexed ions is much greater than the concentration of unbound ions. Because the number of complexed ions along the $c^{*}$ boundary is proportional to protein concentration, decreasing protein concentration has the effect of increasing $c^{f}$ relative to the bound ion concentration, which is reflected by a shift in the curves to the right.

The solubility boundary $c^{*}$ has been fit to equation 2 to obtain $c^{f}=0.3 \pm 0.15 \mathrm{mM}$ and $m^{*}=0.58 \pm 0.06$, and $c^{f}=0.05 \pm 0.03 \mathrm{mM}$ and $m^{*}=0.27 \pm 0.02$ for SPP and for STPP solutions, respectively. The lower value for $m^{*}$ indicates that a smaller number of bound TPP molecules versus PP are required to induce protein precipitation. This can be rationalized in part by the greater negative charge on TPP $(-4.76 e)$ versus SPP $(-3.32 e)$. Binding of 0.27 moles of TPP corresponds to an average reduction in charge approximately equal to $1.3 e$, while the corresponding value for 0.58 moles of pyrophosphate is $1.9 e$. The bare charge of lysozyme at $\mathrm{pH} 9.0$ is near to $+6-7 e$, so that the precipitation boundary occurs when there still exists a net positive charge on lysozyme, which is consistent with the $\zeta$-potential data for STPP in solutions at $1 \mathrm{mg} / \mathrm{mL}$. The slight difference in the charged state of the protein at the $c^{*}$-boundary for SPP versus STPP might be due to a difference in the protein-protein interactions upon binding the multivalent ions.

The values of $m^{*}$ obtained for lysozyme in poly-phosphate solutions are much lower than what was obtained in solutions of $\mathrm{YCl}_{3}$ with BSA, HSA, or ovalbumin, where the $c^{*}$ boundary corresponds to near-neutral protein. ${ }^{50}$ The difference in behaviour provides indirect evidence that the ion-bridging attraction induced by poly-phosphate is stronger than for trivalent cations. The extra attraction is required to overcome the larger repulsive barrier imposed by double layer forces due to the larger protein net charge in polyphosphate solutions along the $c^{*}$ precipitation boundary.

A more direct comparison of the protein-protein interactions in multivalent ion solutions is possible when examining the behaviour at salt concentrations much greater than $c^{*}$ when it is possible to directly measure values of $B_{22}{ }^{33}$ Comparing protein-protein interactions between proteins of different sizes requires using a normalized virial coefficient defined by $b_{22}=B_{22} / B_{22}^{\mathrm{ex}}$, where $B_{22}^{\mathrm{ex}}$ corresponds to the excluded volume contribution. ${ }^{72-}$

${ }^{74}$ While it is not possible to measure $B_{22}^{\text {ex }}$ directly, molecular simulation using all-atomistic representations for proteins indicate the value can be approximated by the excluded volume of a sphere, which has the same hydrodynamic radius as the protein. ${ }^{75}$ In figure 7 the $B_{22} / B_{22}^{\mathrm{HS}}$ values for lysozyme are compared against the measured values for HSA as a function of $\mathrm{YCl}_{3}$ concentration where they have been normalized using a literature value for 
reentrant region for the protein systems, the solid arrow represents region II for $3.1 \mathrm{mg} / \mathrm{mL}$ HSA with $\mathrm{YCl}_{3}$ as determined by turbidity measurements. Dashed and dotted arrows represent region II for $5 \mathrm{mg} / \mathrm{mL}$ lysozyme with SPP or STPP respectively as determined by solubility experiments, which reflects the concentration range between $c^{*}$ and $c^{* *}$ values for $5 \mathrm{mg} / \mathrm{mL}$ lysozyme. The reentrant region III occurs at a slightly higher salt concentrations for lysozyme in poly-phosphate solutions versus HSA in solutions of $\mathrm{YCl}_{3}$.

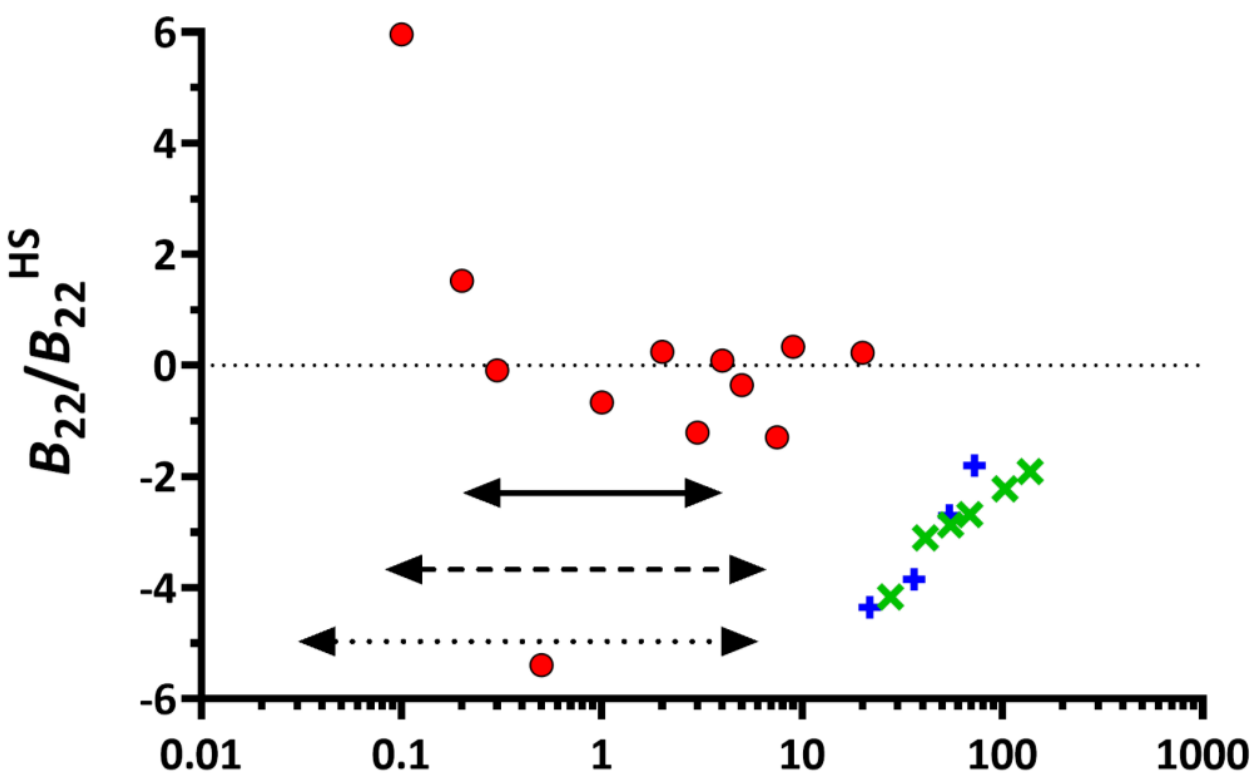

\section{Salt Concentration (mM)}

Figure 7. Plot of the reduced second virial coefficient $B_{22} / B_{22}{ }^{\mathrm{HS}}$ for $\mathrm{HSA}$ with $\mathrm{YCl}_{3}(\bullet)$ and lysozyme with SPP $(\boldsymbol{X})$ and STPP $(\boldsymbol{+})$ in the resolubilisation region. $r_{H}$ values of 3.7 and $1.9 \mathrm{~nm}$ were used for

$\mathrm{HSA}$ and lysozyme respectively in calculating $B_{22}^{\mathrm{HS}}$. The solid arrow represents region II for 3.1 $\mathrm{mg} / \mathrm{mL} \mathrm{HSA}$ with $\mathrm{YCl}_{3}$ as determined by turbidity measurements. Dashed and dotted lines represent region II for $5 \mathrm{mg} / \mathrm{mL}$ lysozyme with SPP or STPP respectively as determined by turbidity experiments for the $c^{*}$ boundary and solubility experiments for the $c^{* *}$ boundary.

The $B_{22}$ values for BSA go through a pronounced minimum at a salt concentration of about $0.5 \mathrm{mM}$, which likely reflects the maximum precipitation point where the protein is near neutral. Our measurements do not exhibit a minimum because they are carried out at a higher salt concentration relative to the maximum precipitation point. Along the $c^{* *}$ boundary, the protein-protein interactions are more attractive for the poly-phosphate solutions as the $B_{22}$ values range from -4 to -2 , while for $\mathrm{YCl}_{3}$ the values change from -1 to 1 . While $b_{22}$ values have not been measured in solutions below a concentration of $20 \mathrm{mM}$ for the poly-phosphate solutions, we expect a decreasing trend until a minimum is reached near to the maximum precipitation point, which is in the region of 1 to $10 \mathrm{mM}$ (see figure 7). 
809

810

811

812

813

814

815

816

817

818

819

820

821

822

823

824

825

826

827

828

829

830

831

832

833

834

835

836

837

838

839

840

841

842

843

844

845

846

847

848

849

As such, a much stronger protein-protein attraction is expected to occur in solutions of polyphosphate ions. The normalized $b_{22}$ values used in this analysis are very sensitive to the choice of sphere size used to represent the protein. Rather than using $R_{\mathrm{h}}$, an alternate definition could be the radius of a sphere that has the same volume of the protein, which would correspond to $2.7 \mathrm{~nm}$ for BSA and $1.7 \mathrm{~nm}$ for lysozyme. Using these values would lead to a larger decrease in the $b_{22}$ values for BSA versus for lysozyme, but would not change the overall trend that protein-protein attractions are generally more attractive in polyphosphate solutions versus in solutions of $\mathrm{YCl}_{3}$.

Interestingly, the protein-protein interactions measured as a function of salt concentration are similar in the STPP and SPP solutions, which is consistent with the finding that there is little effect of changing the multivalent anion on the $c^{* *}$ boundary. At salt concentrations greater than $20 \mathrm{mM}$, it is likely that the binding sites for the multivalent anions on the protein have been saturated since the $\zeta$-potential curves plateau above this concentration. As such, the results appear to indicate the protein-protein interactions are similar for lysozyme complexes with TPP versus with PP. Further investigations would be required to determine whether the individual contributions from the ion-bridging interactions and the overcharging effect are similar for the different poly-phosphate ions. A distinct possibility is that the individual contributions to the ion-bridging interaction and overcharging differ from each other, but the net protein-protein interactions are the same. One might expect that the increased charge of the TPP versus PP would lead to a stronger ion-bridging interaction, but also a stronger over-charging repulsion.

\section{The phase diagram in solutions of multivalent ions}

A comparison between this work and previous work on trivalent cations needs to be made to highlight some of the similarities and disparities between the two systems. In Figure 8 we show a schematic of a protein phase diagram where the y-ordinate corresponds to an equivalent temperature or a measure of the protein-protein interaction strength such as $b_{22}$. The phase diagram, which has been elucidated in detail for lysozyme and $\gamma$ crystallins, includes a liquid-liquid equilibrium, which is metastable to the crystal solubility curve. $^{35,74,78-86}$ The liquid-liquid equilibrium has the same fundamental origin as a vapourliquid transition for a pure fluid. Beneath the binodal is a spinodal, defined by the locus of points where the osmotic compressibility is equal to zero. The spinodal, which bounds the region of instability where solutions spontaneously undergo phase separation, meets the binodal at the critical point. In addition, there is a gel transition that extends into the spinodal. ${ }^{84,87-88}$ 
Figure 8: A schematic of a protein phase diagram where the y-ordinate corresponds to an equivalent temperature or a measure of the protein-protein interaction strength such as

$$
b_{22} \text {. }
$$

In order to further understand the impact of poly-phosphates on the phase diagram, a schematic of the experimentally determined phase diagram for lysozyme in terms of $B_{22}$ is shown in figure 9 . The circles points indicate the solubility of lysozyme crystals under a range of different solution conditions taken from a study by Guo et al 1999, while the diamond points correspond to the dilute branch of the liquid-liquid binodal obtained for lysozyme in solutions with $500 \mathrm{mM}$ sodium chloride. ${ }^{55,84}$ The binodals measured at lower sodium chloride concentrations occur at approximately the same location suggesting there is a universal binodal in terms of $B_{22}$ for lysozyme. The binodal, as expected, occurs at a greater strength of protein-protein attraction and is located below the crystal solubility line. The squares correspond to the $c^{* *}$ boundary determined in this work for solutions containing either STPP or SPP, which is located at even greater strengths of protein-protein attraction when compared against the binodal.

The location of the gel transition relative to the binodal has been investigated for lysozyme by Dumetz et al $2008 .^{87}$ For lysozyme dissolved in sodium chloride solutions, a liquid-liquid equilibrium only occurs below a critical concentration of approximately $1.6 \mathrm{M}$, while above, a solid precipitate is always formed. In contrast, lysozyme always forms a solid 
890

891

892

893

894

895

896

897

898

899

900

901

902

903

904

905

906

907

908

909

910

911

912

913

914

915

916

917

918

919

920

921

922

923

924

925

926

927

928

929

precipitate in ammonium sulfate solution. They showed the type of precipitation is determined by the location relative to the point where the gelation line intersects with the binodal. If solutions are prepared in the spinodal at a location above the intersection point,

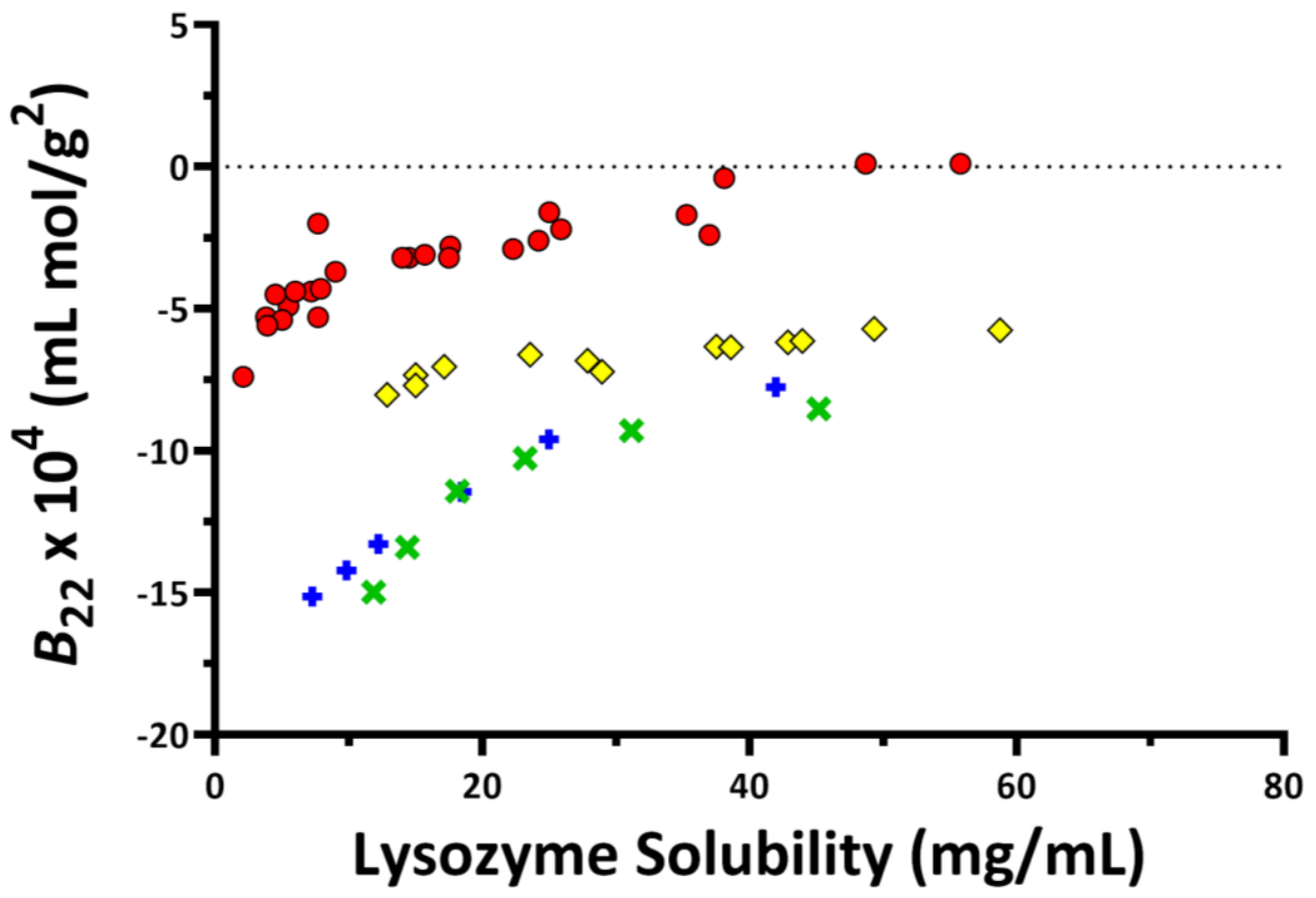

Figure 9. Experimental data for $B_{22}$ values of lysozyme in the presence of SPP ( $\mathbf{X}$ ) and STPP $(+)$, lysozyme crystal solubility from different solution conditions measured by Guo et al $1999(\bullet)$ and the diamonds correspond to the liquid-liquid binodal obtained for lysozyme in solutions with $500 \mathrm{mM}$ sodium chloride Gibaud et al $2011(\diamond) .{ }^{55,84}$

a liquid-liquid equilibrium is formed through spinodal decomposition. However, when preparing solutions at locations below this point, the spinodal decomposition is arrested leading to the formation of a gel phase or an amorphous precipitate, where the coexisting liquid phase is more concentrated than the dilute phase of the binodal located at the same protein-protein interaction strength. The authors indicated that the binodal is absent for lysozyme in ammonium sulfate solutions because the gelation line intersects the binodal to the left of the critical point, in which case, spinodal decomposition is always arrested.

Our experimental evidence suggests that the amorphous precipitate observed for lysozyme in the poly-phosphate solutions is due to a gel transition. The solid precipitate formed by lysozyme has a shiny white appearance, which resembles the observations reported for the lysozyme precipitate in Dumetz et al 2008. ${ }^{87}$ Furthermore, the supernatant phase concentrations obtained from the poly-phosphate experiments are always greater 
than the concentrations along the dilute branch of the binodal when compared at the same value of $B_{22}$, which is expected if the gel transition has interrupted the liquid-liquid transition. ${ }^{84}$ At higher poly-phosphate concentrations, the coexistence curve occurs at values of $B_{22}$ that are similar to the critical point $B_{22}$ in sodium chloride solutions. Because we do not observe any liquid-liquid equilibrium, this suggests that the gelation line has moved to the left of the critical point. This hypothesis assumes that there is a universal binodal in terms of $B_{22}$ for lysozyme under all solvent conditions. The location of the critical point is known to depend on the anisotropy of the interaction potential, where decreasing the anisotropy can shift the critical point to higher values of $B_{22} \cdot{ }^{89-92}$ If this is the case, liquidliquid equilibrium might still be possible in solutions at higher poly-phosphate concentration. However, the protein-protein interactions are likely more, rather than less anisotropic in solutions of multivalent ions, which is supported by the observed shift of the critical point to lower packing fractions for the liquid-liquid equilibrium of BSA induced by adding $\mathrm{YCl}_{3}{ }^{62}$ Nevertheless a more detailed investigation is still required to determine the phase boundaries in particular for solutions corresponding to larger values of $B_{22}$ than the points shown on figure 9 .

946

It is not unreasonable for the location of the gelation line to change relative to the binodal under solution conditions where there is a significant electrostatic repulsion as occurs with poly-phosphate solutions. ${ }^{84}$ This was demonstrated through determining the relative location of the gelation line to the binodal for lysozyme as a function of $\mathrm{NaCl}$ concentration. A near universal relationship between $B_{22}$ and the binodal indicated the liquid-liquid equilibrium depends on the integrated form of the total protein-protein interaction, which includes an ionic-strength independent short-ranged attraction and a long ranged repulsion that increases with decreasing salt concentration. On the other hand, the gel transition was found to only depend on the magnitude of the short-ranged proteinprotein attraction. As a consequence, the gel transition moves to the left of the binodal when decreasing ionic strength, because there is a greater contribution from the shortranged attraction required to balance the increase in the long-ranged electrostatic repulsion to obtain the same $B_{22}$. Overall, this suggests the liquid-liquid equilibrium could be obtained by weakening the short-ranged attraction in the poly-phosphate solutions. This indeed is consistent with a recent study examining how the phase behaviour of $\mathrm{BSA}$ changes in $\mathrm{YCl}_{3}$ solutions as a function of the deuterated water content. ${ }^{26}$ At high levels of deuterated water, the behaviour resembles what we observe in poly-phosphate solutions, where the absence of a liquid-liquid equilibrium corresponds to stronger short-ranged protein-protein attraction (as quantified in terms of $B_{22}$ measurements) and an increase in the size of region II in in the phase diagram. 


\section{Difference between citrate and SPP}

Citrate reduces and inverts the net charge of lysozyme in a similar manner to SPP and STPP but does not induce reentrant condensation, despite citrate and SPP being of similar shape, size and charge. The explanation as to why citrate does not induce lysozyme reentrant condensation and PP does cannot be explained solely in terms of electrostatics as lysozyme zeta potentials for both anions are similar; this suggests their different behaviours can be explained by differences in their specific chemistry which determines how they interact with lysozyme.

First, the $\mathrm{P}^{-} \mathrm{O}^{-}$bonds in $\mathrm{PP}$ are more polarised than the $\mathrm{C}^{-} \mathrm{O}^{-}$groups in citrate which would result in stronger electrostatic interactions between SPP and the solvent exposed basic residues of lysozyme compared to those the carboxylate groups of citrate can form. These stronger electrostatic interactions formed by PP would enable lysozyme crosslinking. Second, carboxylate and phosphate groups have different hybridisations (shapes) which could allow them to interact with basic residues differently. These differences are highlighted by a body of literature investigating how hydrogen bond donors (HBD), metal cations and covalent bonds form between sulfate, phosphate and carboxylate groups. ${ }^{93-96}$ This work shows that phosphate-HBD geometry is different to carboxylate-HBD. ${ }^{93,96}$ Interactions between carboxylate groups and hydrogen bond donors/some metal cations were found to be highly directional. ${ }^{93}$ Unlike carboxylates, interactions between phosphates and hydrogen bond donors were found to be less directional; they show almost equal preference for anti-orientation and syn-orientation interactions and no preference for inplane interactions; this could explain why PP induces reentrant condensation and citrate does not. ${ }^{93}$ It is possible that the highly directional orientation required for citrate-HBD interactions prevents citrate from crosslinking lysozyme molecules because the required orientations are sterically hindered. ${ }^{95}$ For the phosphate groups of PP the interactions with the basic residues are less directional; which means there should be less steric hindrance associated with crosslinking lysozyme molecules together which makes it more favourable.

\section{Conclusions}

In summary, we have shown anions with higher valencies are more effective at reducing lysozyme-lysozyme repulsion under low ionic strength conditions by altering electrostatic interactions between lysozyme molecules, where multivalent anions cause reversal of lysozyme net charge and overcharging at high ionic strengths. The degree of lysozyme charge inversion was determined by anion valency and follows the order TPP > PP $>$ citrate $>$ sulfate $>$ chloride. The poly-phosphates SPP and STPP induced precipitation of 1$100 \mathrm{mg} / \mathrm{mL}$ lysozyme at low concentrations through an ion-bridging attraction, which is stronger than that observed with trivalent cations and negatively charged proteins. Resolubilization of the precipitate occurs at higher ion concentration most likely due to an 
1012 overcharging effect. We suggest that the precipitate formed in region II is due to a gel 1013 transition formed through spinodal decomposition. Interestingly, we do not observe any 1014 ion-bridging attraction or reentrant condensation behaviour for lysozyme in solutions 1015 containing citrate even though citrate has a similar effectiveness as pyrophosphate at 1016 neutralizing lysozyme charge.

1017

1018 Acknowledgments

1019 This work was supported by the Engineering and Physical Sciences Research Council (EPSRC) 1020 grant EP/N024796/1.

1021

1022

1023

1024

1025

1026

1027

1028

1029

1030

1031

1032

1033

1034

1035

1036

1037

1038

1039 
1040

1041

1042

1043

1044

1045

1046

1047

1048

1049

1050

1051

1052

1053

1054

1055

1056

1057

1058

1059

1060

1061

1062

1063

1064

1065

1066

1067

1068

1069

1070

1071

1072

1073

1074

1075

1076

1077

1078

1079

1080

1081

1082

1083

1084

\section{References}

(1) Mittheilung, Z.; Hofmeister, F. Zur Lehre von der Wirkung der Salze. Arch. Exptl. Pathol. Pharmakol. 1888, 25, 1-30.

(2) Kunz, W.; Henle, J.; Ninham, B. W. 'Zur Lehre von der Wirkung der Salze' (about the science of the effect of salts): Franz Hofmeister's historical papers. Curr. Opin. Colloid. In. 2004, 9, 19-37.

(3) Cox, W. M.; Wolfenden, J. H. The Viscosity of Strong Electrolytes Measured by a Differential Method. P. R. Soc. A. 1934, 145, 475-488.

(4) Marcus, Y. Effect of Ions on the Structure of Water: Structure Making and Breaking. Chem. Rev. 2009, 109, 1346-1370.

(5) Stradner, A.; Sedgwick, H.; Cardinaux, F.; Poon, W. C. K.; Egelhaaf, S. U.; Schurtenberger, P. Equilibrium cluster formation in concentrated protein solutions and colloids. Nature. 2004, 432, 492-495.

(6) Roosen-Runge, F.; Zhang, F.; Schreiber, F.; Roth, R. Ion-activated attractive patches as a mechanism for controlled protein interactions. Sci. Rep-UK. 2014, 4, 7016.

(7) Roberts, D.; Keeling, R.; Tracka, M.; Van Der Walle, C.; Uddin, S.; Warwicker, J.; Curtis, R. The role of electrostatics in protein-protein interactions of a monoclonal antibody. Mol. Pharm. 2014, 11, 2475-2489.

(8) Roberts, D.; Keeling, R.; Tracka, M.; Van Der Walle, C.; Uddin, S.; Warwicker, J.; Curtis, R. Specific ion and buffer effects on protein-protein interactions of a monoclonal antibody. Mol. Pharm. 2014, 12, 179-193.

(9) Perez-Jimenez, R.; Godoy-Ruiz, R.; Ibarra-Molero, B.; Sanchez-Ruiz, J. M. The Efficiency of Different Salts to Screen Charge Interactions in Proteins: A Hofmeister Effect? Biophys. J. 2004, 86, 2414-2429.

(10) Zhou, H.-X.; Pang, X. Electrostatic Interactions in Protein Structure, Folding, Binding, and Condensation. Chem. Rev. 2018, 118, 1691-1741.

(11) Hyman, A. A.; Weber, C. A.; Jülicher, F. Liquid-Liquid Phase Separation in Biology. Annu. Rev. Cell. Dev. Bi. 2014, 30, 39-58.

(12) Boeynaems, S.; Alberti, S.; Fawzi, N. L.; Mittag, T.; Polymenidou, M.; Rousseau, F.; Schymkowitz, J.; Shorter, J.; Wolozin, B.; Van Den Bosch, L.; Tompa, P.; Fuxreiter, M. Protein Phase Separation: A New Phase in Cell Biology. Trends. Cell. Bio. 2018, 28, 420-435.

(13) Patel, A.; Malinovska, L.; Saha, S.; Wang, J.; Alberti, S.; Krishnan, Y.; Hyman, A. A. ATP as a biological hydrotrope. Science. 2017, 356, 753-756.

(14) Jungwirth, P.; Cremer, P. S. Beyond Hofmeister. Nat. Chem. 2014, 6, 261-263.

(15) Bye, J. W.; Baxter, N. J.; Hounslow, A. M.; Falconer, R. J.; Williamson, M. P. Molecular Mechanism for the Hofmeister Effect Derived from NMR and DSC Measurements on Barnase. ACS Omega. 2016, 1, 669-679.

(16) C. P. Schneider; D. Shukla; B. L. Trout. Arginine and the Hofmeister Series: the role of ion-ion interactions in protein aggregation suppression. J. Phys. Chem. B. 2011, 115, 74477458.

(17) Bye, J. W.; Falconer, R. J. Thermal stability of lysozyme as a function of ion concentration: A reappraisal of the relationship between the Hofmeister series and protein stability. Protein. Sci. 2013, 22, 1563-1570.

(18) Kastelic, M.; Kalyuzhnyi, Y. V.; Hribar-Lee, B.; Dill, K. A.; Vlachy, V. Protein aggregation in salt solutions. Proc. Natl. Acad. Sci. U. S. A. 2015, 112, 6766-6770. 
1085

1086

1087

1088

1089

1090

1091

1092

1093

1094

1095

1096

1097

1098

1099

1100

1101

1102

1103

1104

1105

1106

1107

1108

1109

1110

1111

1112

1113

1114

1115

1116

1117

1118

1119

1120

1121

1122

1123

1124

1125

1126

1127

1128

1129

1130
(19) Von Hippel, P. H.; Schleich, T. Ion Effects on the Solution Structure of Biological Macromolecules. Accounts. Chem. Res. 1969, 2, 257-265.

(20) Heydweiller, A. Concerning the physical characteristics of solutions in correlation. II. Surface tension and electronic conductivity of watery salt solutions. Ann. Phys-Berlin. 1910, 33, 145-185.

(21) Omta, A. W.; Kropman, M. F.; Woutersen, S.; Bakker, H. J. Negligible effect of ions on the hydrogen-bond structure in liquid water. Science. 2003, 301, 347-349.

(22) dos Santos, A. P.; Diehl, A.; Levin, Y. Surface tensions, surface potentials, and the Hofmeister series of electrolyte solutions. Langmuir. 2010, 26, 10778-10783.

(23) Bye, J. W.; Falconer, R. J. Three Stages of Lysozyme Thermal Stabilization by High and Medium Charge Density Anions. J. Phys. Chem. B. 2014, 118, 4282-4286.

(24) Record, M. T.; Guinn, E.; Pegram, L.; Capp, M. Introductory Lecture: Interpreting and predicting Hofmeister salt ion and solute effects on biopolymer and model processes using the solute partitioning model. Faraday. Discuss. 2013, 160, 9-44.

(25) von Hippel, Peter H. Changing the Stability of Macromolecular Surfaces by Manipulating the Aqueous Environment. Biophys. J. 2016, 111, 1817-1820.

(26) Matsarskaia, O.; Braun, M. K.; Roosen-Runge, F.; Wolf, M.; Zhang, F.; Roth, R.; Schreiber, F. Cation-Induced Hydration Effects cause lower critical solution temperature behavior in protein solutions. J. Phys. Chem. B. 2016, 120, 7731-7736.

(27) Ries-Kautt, M. M.; Ducruix, A. F. Relative Effectiveness of Various lons on the Solubility and Crystal Growth of Lysozyme. J. Biol. Chem. 1989, 264, 745-748.

(28) Zhang, Y.; Cremer, P. S. The inverse and direct Hofmeister series for lysozyme. Proc. Natl. Acad. Sci. U. S. A. 2009, 106, 15249-15253.

(29) Ramos, C. H.; Baldwin, R. L. Sulfate anion stabilization of native ribonuclease A both by anion binding and by the Hofmeister effect. Protein. Sci. 2002, 11, 1771-1778.

(30) Zhang, F.; Skoda, M. W. A.; Jacobs, R. M. J.; Zorn, S.; Martin, R. A.; Martin, C. M.; Clark, G. F.; Weggler, S.; Hildebrandt, A.; Kohlbacher, O.; Schreiber, F. Reentrant Condensation of Proteins in Solution Induced by Multivalent Counterions. Phys. Rev. Lett. 2008, 101, 148101.

(31) Bye, J. W.; Cowieson, N. P.; Cowieson, A. J.; Selle, P. H.; Falconer, R. J. Dual effects of sodium phytate on the structural stability and solubility of proteins. J. Agr. Food. Chem. 2013, 61, 290-295.

(32) Bostrom, M.; Parsons, D. F.; Salis, A.; Ninham, B. W.; Monduzzi, M. Possible origin of the inverse and direct Hofmeister series for lysozyme at low and high salt concentrations. Langmuir. 2011, 27, 9504-9511.

(33) Wolf, M.; Roosen-Runge, F.; Zhang, F.; Roth, R.; Skoda, M. W.; Jacobs, R. M.; Sztucki, M.; Schreiber, F. Effective interactions in protein-salt solutions approaching liquid-liquid phase separation. J. Mol. Liq. 2014, 200, 20-27.

(34) Reiche, K.; Hartl, J.; Blume, A.; Garidel, P. Liquid-liquid phase separation of a monoclonal antibody at low ionic strength: Influence of anion charge and concentration. Biophys. Chem. 2017, 220, 7-19.

(35) McManus, J. J.; Lomakin, A.; Ogun, O.; Pande, A.; Basan, M.; Pande, J.; Benedek, G. B. Altered phase diagram due to a single point mutation in human $\gamma \mathrm{D}$-crystallin. Proc. Natl. Acad. Sci. U. S. A. 2007, 104, 16856-16861.

(36) Bostrom, M.; Tavares, F. W.; Finet, S.; Skouri-Panet, F.; Tardieu, A.; Ninham, B. W. Why forces between proteins follow different Hofmeister series for $\mathrm{pH}$ above and below $\mathrm{pl}$. Biophys. Chem. 2005, 117, 217-224. 
(37) Grigsby, J. J.; Blanch, W. H.; Prausnitz, J. M. Cloud-point temperatures for lysozyme in electrolyte solutions: effect of salt type, salt concentration and pH. Biophys. Chem. 2001, 91, 213-243.

(38) Lund, M.; Jungwirth, P. Ion Specific Protein Assembly and Hydrophobic Surface Forces. Phys. Rev. Lett. 2008, 100, 258105-258109.

(39) Curtis, R. A.; Ulrich, J.; Montaser, A.; Prausnitz, J. M.; Blanch, H. W. Protein-protein interactions in concentrated electrolyte solutions. Biotechnol. Bioeng. 2002, 79, 367-380.

(40) Pasquier, C.; Vazdar, M.; Forsman, J.; Jungwirth, P.; Lund, M. Anomalous ProteinProtein Interactions in Multivalent Salt Solution. J. Phys. Chem. B. 2017, 121, 3000-3006.

(41) Antonov, M.; Mazzawi, M.; Dubin, P. L. Entering and Exiting the Protein-Polyelectrolyte Coacervate Phase via Nonmonotonic Salt Dependence of Critical Conditions. Biomacromolecules. 2010, 11, 51-59.

(42) Palmeira-de-Oliveira, R.; Palmeira-de-Oliveira, A.; Gaspar, C.; Silvestre, S.; Martinezde-Oliveira, J.; Amaral, M. H.; Breitenfeld, L. Sodium Tripolyphosphate: An excipient with intrinsic in vitro anti-Candida activity. Int. J. Pharm. 2011, 421, 130-134.

(43) Office, L. S. R. Evaluation of Health Aspects of Phosphates as Food Ingredients. Food and Drug Administration. 1975, SCOGS-32, 48.

(44) Lampila, L. E. Functions and Uses of Phosphates in the Seafood Industry. J. Aquat. Food. Prod. T. 1993, 1, 29-41.

(45) Deshpande, S. S.; Cheryan, M. Effects of Phytic Acid, Divalent Cations, and their interactions on alpha amylase activity Desphande. J. Food. Sci. 1984, 49, 516-519.

(46) Selle, P. H.; Cowieson, A. J.; Cowieson, N. P.; Ravindran, V. Protein-phytate interactions in pig and poultry nutrition: a reappraisal. Nutr. Res. Rev, . 2012, 25, 1-17.

(47) Champagne, E. T.; Rao, R. M.; Liuzzo, J. A.; Robinson, J. W.; Gale, R. J.; Miller, F. The interactions of Minerals, Proteins and Phytic Acid in Rice Bran. Cereal. Chem. 1985, 62, 231238.

(48) Coweison, A. J.; Acamovic, T.; Bedford, M. R. Phytic Acid and Phytase: Implications for Protein Utilization by Poultry. J. Poult. Sci. 2005, 85, 878-885.

(49) Cheryan, M.; Rackis, J. J. Phytic Acid Interactions in Food Systems. CRC. CR. Rev. Food. Sci. 1980, 13, 297-335.

(50) Zhang, F.; Weggler, S.; Ziller, M. J.; laneselli, L.; Heck, B. S.; Hildebrandt, A.; Kohlbacher, O.; Skoda, M. W. A.; Jacobs, R. M. J.; Schreiber, F. Universality of protein reentrant condensation in solution induced by multivalent metal ions. Proteins. 2010, 78, 3450-3457.

(51) Ścibisz, G.; Dec, R.; Dzwolak, W. Mellitate: A multivalent anion with extreme charge density causes rapid aggregation and misfolding of wild type lysozyme at neutral $\mathrm{pH}$. PLOS ONE. 2017, 12, e0187328.

(52) Deshpande, S. S.; Damodaran, S. Effect of Phytate on Solubility, Activity and Conformation of trypsin and chymotrypsin Desphande. J. Food. Sci. 1989, 54, 695-699.

(53) Corbridge, D. E. C. Phosphorus. An outline of its chemistry, biochemistry, and technology. Elsevier Scientific Publishers B.V.: 1985; 777.

(54) Li, W.; Persson, B. A.; Morin, M.; Behrens, M. A.; Lund, M.; Zackrisson Oskolkova, M. Charge-Induced Patchy Attractions between Proteins. J. Phys. Chem. B. 2015, 119, 503-508.

(55) Guo, B.; Kao, S.; McDonald, H.; Asanov, A.; Combs, L. L.; William Wilson, W. Correlation of second virial coefficients and solubilities useful in protein crystal growth. J. Cryst. Growth. 1999, 196, 424-433. 
(56) Kuehner, D. E.; Engmann, J.; Fergg, F.; Wernick, M.; Blanch, H. W.; Prausnitz, J. M. Lysozyme Net Charge and Ion Binding in Concentrated Aqueous Electrolyte Solutions. J. Phys. Chem. B. 1999, 103, 1368-1374.

(57) Lund, M. Anisotropic protein-protein interactions due to ion binding. Colloid. Surface.

(58) Velev, O. D.; Kaler, E. W.; Lenhoff, A. M. Protein Interactions in Solution Characterized by Light and Neutron Scattering: Comparison of Lysozyme and Chymotrypsinogen. Biophys. J. 1998, 75, 2682-2697.

(59) Yatin, R. G.; Fesinmeyer, M. R.; Saluja, A.; Razinkov, V.; Chase, S. F.; Laue, T. M.; Brems, D. N. Effective charge measurements reveal selective and preferential accumulation of anions, but not cations, at the protein surface in dilute salt solutions. Protein. Sci. 2011, 20, 580-587.

(60) Mason, P. E.; Dempsey, C. E.; Vrbka, L.; Heyda, J.; Brady, J. W.; Jungwirth, P. Specificity of Ion-Protein Interactions: Complementary and Competitive Effects of Tetrapropylammonium, Guanidinium, Sulfate, and Chloride Ions. J. Phys. Chem. B. 2009, 113, 3227-3234.

(61) Cosgrove, D. J. The Chemistry and Biochemistry of Inositol Polyphosphates. Pure. Appl. Chem. 1966, 16, 209-224.

(62) Zhang, F.; Roth, R.; Wolf, M.; Roosen-Runge, F.; Skoda, M. W. A.; Jacobs, R. M. J.; Stzucki, M.; Schreiber, F. Charge-controlled metastable liquid-liquid phase separation in protein solutions as a universal pathway towards crystallization. Soft Matter. 2012, 8, 13131316.

(63) Jordan, E.; Roosen-Runge, F.; Leibfarth, S.; Zhang, F.; Sztucki, M.; Hildebrandt, A.; Kohlbacher, O.; Schreiber, F. Competing Salt Effects on Phase Behavior of Protein Solutions: Tailoring of Protein Interaction by the Binding of Multivalent lons and Charge Screening. J. Phys. Chem. B. 2014, 118, 11365-11374.

(64) Muschol, M.; Rosenberger, F. Interactions in undersaturated and supersaturated lysozyme solutions: Static and dynamic light scattering results. J. Chem. Phys. 1995, 103, 10424-10432.

(65) Eberstein, W.; Georgalis, Y.; Saenger, W. Molecular interactions in crystallizing lysozyme solutions studied by photon correlation spectroscopy. J. Cryst. Growth. 1994, 143, 71-78.

(66) Neal, B. L.; Asthagiri, D.; Velev, O. D.; Lenhoff, A. M.; Kaler, E. W. Why is the osmotic second virial coefficient related to protein crystallization? J. Cryst. Growth. 1999, 196, 377387.

(67) Elcock, A. H.; McCammon, J. A. Calculation of Weak Protein-Protein Interactions: The pH Dependence of the Second Virial Coefficient. Biophys. J. 2001, 80, 613-625.

(68) Pellicane, G.; Smith, G.; Sarkisov, L. Molecular Dynamics Characterization of Protein Crystal Contacts in Aqueous Solutions. Phys. Rev. Lett. 2008, 101, 248102.

(69) Quang, L. J.; Sandler, S. I.; Lenhoff, A. M. Anisotropic Contributions to Protein-Protein Interactions. J. Chem. Theory. Comput. 2014, 10, 835-845.

(70) Kundu, S.; Das, K.; Aswal, V. K. Modification of attractive and repulsive interactions among proteins in solution due to the presence of mono-, di- and tri-valent ions. Chem. Phys. Lett. 2013, 578, 115-119.

(71) Zhang, F.; Zocher, G.; Sauter, A.; Stehle, T.; Schreiber, F. Novel approach to controlled protein crystallization through ligandation of yttrium cations. J. Appl. Crystallogr. 2011, 44, 755-762. 
(72) Baxter, R. J. Percus-Yevick Equation for Hard Spheres with Surface Adhesion. J. Chem. Phys. 1968, 49, $2770-2774$.

(73) Vliegenthart, G. A.; Lekkerkerker, H. N. W. Predicting the gas-liquid critical point from the second virial coefficient. J. Chem. Phys. 2000, 112, 5364-5369.

(74) Rosenbaum, D.; Zamora, P. C.; Zukoski, C. F. Phase Behavior of Small Attractive Colloidal Particles. Phys. Rev. Lett. 1996, 76, 150-153.

(75) Grünberger, A.; Lai, P.-K.; Blanco, M. A.; Roberts, C. J. Coarse-Grained Modeling of Protein Second Osmotic Virial Coefficients: Sterics and Short-Ranged Attractions. J. Phys. Chem. B. 2013, 117, 763-770.

(76) Meechai, N.; Jamieson, A. M.; Blackwell, J. Translational Diffusion Coefficients of Bovine Serum Albumin in Aqueous Solution at High Ionic Strength. J. Colloid. Interf. Sci. 1999, 218, 167-175.

(77) Parmar, A. S.; Muschol, M. Hydration and Hydrodynamic Interactions of Lysozyme: Effects of Chaotropic versus Kosmotropic lons. Biophys. J. 2009, 97, 590-598.

(78) Curtis, R. A.; Lue, L. A molecular approach to bioseparations: Protein-protein and protein-salt interactions. Chem. Eng. Sci. 2006, 61, 907-923.

(79) Rosenbaum, D. F.; Kulkarni, A.; Ramakrishnan, S.; Zukoski, C. F. Protein interactions and phase behavior: Sensitivity to the form of the pair potential. J. Chem. Phys. 1999, 111, 9882-9890.

(80) Taratuta, V. G.; Holschbach, A.; Thurston, G. M.; Blankschtein, D.; Benedek, G. B. Liquid-liquid phase separation of aqueous lysozyme solutions: effects of $\mathrm{pH}$ and salt identity. J. Phys. Chem-US. 1990, 94, 2140-2144.

(81) Muschol, M.; Rosenberger, F. Liquid-liquid phase separation in supersaturated lysozyme solutions and associated precipitate formation/crystallization. J. Chem. Phys. 1997, 107, 1953-1962.

(82) Schurtenberger, P.; Chamberlin, R. A.; Thurston, G. M.; Thomson, J. A.; Benedek, G. B. Observation of critical phenomena in a protein-water solution. Phys. Rev. Lett. 1989, 63, 2064-2067.

(83) Gögelein, C.; Wagner, D.; Cardinaux, F.; Nägele, G.; Egelhaaf, S. U. Effect of glycerol and dimethyl sulfoxide on the phase behavior of lysozyme: Theory and experiments. $J$. Chem. Phys. 2012, 136, 015102.

(84) Gibaud, T.; Cardinaux, F.; Bergenholtz, J.; Stradner, A.; Schurtenberger, P. Phase separation and dynamical arrest for particles interacting with mixed potentials-the case of globular proteins revisited. Soft Matter. 2011, 7, 857-860.

(85) Broide, M. L.; Berland, C. R.; Pande, J.; Ogun, O. O.; Benedek, G. B. Binary-liquid phase separation of lens protein solutions. Proc. Natl. Acad. Sci. U. S. A. 1991, 88, 5660-5664.

(86) Berland, C. R.; Thurston, G. M.; Kondo, M.; Broide, M. L.; Pande, J.; Ogun, O.; Benedek, G. B. Solid-liquid phase boundaries of lens protein solutions. Proc. Natl. Acad. Sci. U. S. A. 1992, 89, 1214-1218.

(87) Dumetz, A. C.; Chockla, A. M.; Kaler, E. W.; Lenhoff, A. M. Protein Phase Behavior in Aqueous Solutions: Crystallization, Liquid-Liquid Phase Separation, Gels, and Aggregates. Biophys. J. 2008, 94, 570-583.

(88) Cardinaux, F.; Gibaud, T.; Stradner, A.; Schurtenberger, P. Interplay between Spinodal Decomposition and Glass Formation in Proteins Exhibiting Short-Range Attractions. Phys. Rev. Lett. 2007, 99, 118301.

(89) Sear, R. P. Phase behavior of a simple model of globular proteins. J. Chem. Phys. 1999, $111,4800-4806$. 
1286

1287

1288

1289

1290

1291

1292

1293

1294

1295

1296

1297

1298

1299

1300

1301

1302
(90) Kern, N.; Frenkel, D. Fluid-fluid coexistence in colloidal systems with short-ranged strongly directional attraction. J. Chem. Phys. 2003, 118, 9882-9889.

(91) Liu, H.; Kumar, S. K.; Sciortino, F. Vapor-liquid coexistence of patchy models: Relevance to protein phase behavior. J. Chem. Phys. 2007, 127, 084902.

(92) Bianchi, E.; Blaak, R.; Likos, C. N. Patchy colloids: state of the art and perspectives. Phys. Chem. Chem. Phys. 2011, 13, 6397-6410.

(93) Alexander, R. S.; Kanyo, Z. F.; Chirlian, L. E.; Christianson, D. W. Stereochemistry of phosphate-Lewis acid interactions: implications for nucleic acid structure and recognition. J. Am. Chem. Soc. 1990, 112, 933-937.

(94) Kanyo, Z. F.; Christianson, D. W. Biological recognition of phosphate and sulfate. J. Biol. Chem. 1991, 266, 4264-8.

(95) Carrell, C. J.; Carrell, H. L.; Erlebacher, J.; Glusker, J. P. Structural aspects of metal ion carboxylate interactions. J. Am. Chem. Soc. 1988, 110, 8651-8656.

(96) Gandour, R. D. On the importance of orientation in general base catalysis by carboxylate. Bioorg. Chem. 1981, 10, 169-176. 
1303

1304

1305

1306

1307 TOC Graphic

1308

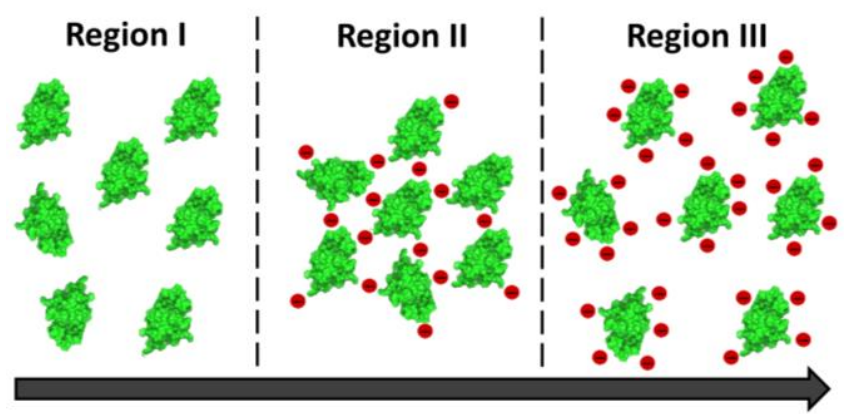

Increasing Sodium Tripolyphosphate Concentration

1314 